\title{
Article
}

\section{The effect of gas phase flame retardants on fire effluent toxicity}

Molyneux, Shirley, Stec, Anna A and Hull, T Richard

Available at http://clok.uclan.ac.uk/12978/

Molyneux, Shirley, Stec, Anna A ORCID: 0000-0002-6861-0468 and Hull, T Richard ORCID: 0000-0002-7970-4208 (2014) The effect of gas phase flame retardants on fire effluent toxicity. Polymer Degradation and Stability, 106 . pp. 36-46. ISSN 0141-3910

It is advisable to refer to the publisher's version if you intend to cite from the work. http://dx.doi.org/10.1016/j.polymdegradstab.2013.09.013

For more information about UCLan's research in this area go to

http://www.uclan.ac.uk/researchgroups/ and search for < name of research Group>.

For information about Research generally at UCLan please go to http://www.uclan.ac.uk/research/

All outputs in CLoK are protected by Intellectual Property Rights law, including Copyright law. Copyright, IPR and Moral Rights for the works on this site are retained by the individual authors and/or other copyright owners. Terms and conditions for use of this material are defined in the policies page.

\section{CLoK}

Central Lancashire online Knowledge www.clok.uclan.ac.uk

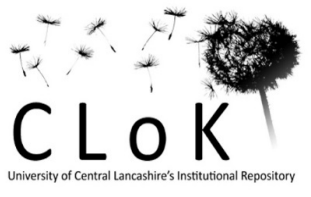




\section{The effect of gas phase flame retardants on fire effluent toxicity}

Shirley Molyneux, Anna A Stec, T Richard Hull, Centre for Fire and Hazards Science, University of Central Lancashire, Preston, PR1 2HE, UK

\section{Abstract}

Standard industry formulations of flame retarded aliphatic polyamides, meeting UL 94 V-0, have been burned under controlled conditions, and the yields of the major asphyxiants, carbon monoxide (CO) and hydrogen cyanide ( $\mathrm{HCN}$ ) have been quantified. Although both the combination of aluminium phosphinate and melamine polyphosphate, and the combination of brominated polystyrene and antimony oxide, inhibit combustion reactions in the gas phase, this study shows that the phosphorus causes a much smaller increase in the $\mathrm{CO}$ and HCN yields than antimonybromine. The mechanisms of $\mathrm{CO}$ and $\mathrm{HCN}$ generation and destruction are related to the flame inhibition reactions. Both $\mathrm{CO}$ and $\mathrm{HCN}$ form early in the flame, and the $\mathrm{OH}$ radical is critical for their destruction. Crucial, in the context of the flame inhibition mechanism, is the observation that the phosphorus system reduces the $\mathrm{H}$ and $\mathrm{O}$ radical concentrations without a corresponding decrease in the $\mathrm{OH}$ radical concentration; conversely, the bromine system reduces all three of the key radical concentrations, $\mathrm{H}, \mathrm{O}$ and $\mathrm{OH}$, and thus increases the fire toxicity, by inhibiting decomposition of $\mathrm{CO}$ and HCN. Moreover, while the phosphorus flame retardant is effective as an ignition suppressant at lower temperatures (corresponding to early flaming), this is effect "switches off" at high temperatures, minimising the potential increase in fire toxicity, once the fire develops. Since flame retardants are most effective as ignition suppressants, and at the early stages of flaming combustion, while most fire deaths and injuries result from toxic gas inhalation from more developed fires, it is clearly advantageous to have an effective gas phase flame retardant which only causes a small increase in the toxic product yields.

\section{Keywords}

Polyamide, brominated, phosphinated, flame, retardant, toxic. 


\section{Introduction}

\subsection{Fire Hazards}

UK fire statistics [1] show that the main cause of death in fires, and the main cause of injury, arises from the inhalation of toxic effluents. To assess the contribution of a material, or a composite article (such as a chair or a fuse box) to the fire toxicity, it is necessary to know both the rate of fire growth and the yields of the different toxicants. The composition of these effluents depends on the chemical formulation of the burning material, oxygen supply, temperature and heating rate $[2,3]$. The most toxicologically significant products are asphyxiant gases and incapacitating irritants. The asphyxiants, carbon monoxide (CO) and hydrogen cyanide ( $\mathrm{HCN})$, decrease the oxygen supply to body tissue resulting in central-nervous-system depression, loss of consciousness and ultimately death. Irritant gases, such as acid gases, hydrogen chloride $(\mathrm{HCl})$ and hydrogen bromide $(\mathrm{HBr})$, certain hydrocarbons and their oxygenated decomposition products, cause immediate incapacitation, mainly by their effects on the eyes and upper respiratory tract, followed by longer term damage deeper in the lung [4].

Certain fire retardants inhibit the free radical reactions typical of flaming combustion. These gas phase "flame retardants" have been shown to increase the yield of carbon monoxide and hydrogen cyanide, both products of incomplete combustion $[5,6]$.

Fires can be divided into a number of stages from smouldering combustion and early well-ventilated flaming, through to fully developed under-ventilated flaming (Table 1) [7]. A useful concept in characterising the gas phase flaming combustion conditions, and predicting the yields of products such as carbon monoxide $(\mathrm{CO})$, carbon dioxide $\left(\mathrm{CO}_{2}\right)$, hydrogen cyanide $(\mathrm{HCN})$ and hydrocarbons, is the equivalence ratio $(\phi)$, presented in Equation 1 [8].

Table 1 Stages of a fire (adapted from ISO classification)[7]

\begin{tabular}{|c|c|c|c|c|}
\hline \multirow[t]{3}{*}{ Fire Stage } & \multicolumn{2}{|c|}{ Max Temp $I^{\circ} \mathrm{C}$} & \multicolumn{2}{|c|}{ Typical values } \\
\hline & & & \multirow{2}{*}{$\begin{array}{c}\text { Equivalence } \\
\text { ratio } \\
\phi\end{array}$} & \multirow{2}{*}{$\begin{array}{c}\mathrm{CO}_{\text {ratio }} \\
\text { ratio }\end{array}$} \\
\hline & Fuel & Smoke & & \\
\hline \multicolumn{5}{|l|}{ Non-flaming } \\
\hline $\begin{array}{l}\text { 1a. Self-sustained oxidative } \\
\text { pyrolysis (e.g. smouldering) }\end{array}$ & $450-800$ & $25-85$ & - & $0.1-1$ \\
\hline \multicolumn{5}{|l|}{ Well ventilated flaming } \\
\hline 2. Well ventilated flaming & $350-650$ & $50-500$ & $0.5-0.7$ & $<0.05$ \\
\hline \multicolumn{5}{|l|}{ Under ventilated Flaming } \\
\hline 3a. Low ventilation room fire & $300-600$ & $50-500$ & $1.5-2$ & $0.2-0.4$ \\
\hline 3b. Post flashover & $350-650$ & $>600$ & $1.5-2$ & $0.1-0.4$ \\
\hline
\end{tabular}




$$
\phi=\frac{\text { actual fuel to air ratio }}{\text { stoichiometric fuel to air ratio }}
$$

$$
\begin{aligned}
& \phi=1 \quad \text { "stoichiometric" combustion } \\
& \phi<1 \quad \text { well }- \text { ventilated fires (fuel lean flames) } \\
& \phi>1 \quad \text { under - ventilated fires (fuel rich flames) }
\end{aligned}
$$

Equation 1

When assessing fire toxicity, the toxic product yields show the greatest sensitivity to the combustion conditions. It is important to ensure that these are relevant to the full-scale fire scenario. It is therefore essential to the assessment of toxic hazard from fire that each fire stage can be adequately replicated, and preferably separating the individual fire stages. A number of different methods exist to assess fire toxicity [9], but most fail to relate the toxicity or toxic product yields to particular fire scenarios, or to replicate the most toxic under-ventilated conditions [3]. The steady state tube furnace (SSTF), ISO/DIS 19700 [10], was specifically designed to replicate individual fire stages. It is a bench scale tube furnace through which an $800 \mathrm{~mm}$ length of sample is driven at a fixed rate, inside a quartz boat. It is supplied with a fixed flow of primary air and the equivalence ratio, $\phi$, can be controlled, in order to replicate different ventilation conditions. The heat fluxes in the SSTF have been reported [11]: at a furnace temperature of $650{ }^{\circ} \mathrm{C}$ the heat flux was $40 \mathrm{~kW} \mathrm{~m}^{-2}$; at a furnace temperature of $825^{\circ} \mathrm{C}$ the heat flux was $77 \mathrm{~kW} \mathrm{~m}^{-2}$.

\subsection{Fire Toxicity}

The contribution of individual toxicants to the overall toxicity can be expressed as a fractional effective dose (FED), described in an additive model of toxicity, as shown in Equation 2, based on rat lethality data to predict the toxicity of a fire effluent, ISO 13344 [12]. The concentration of each toxicant, $\mathrm{X}$, is represented by $[\mathrm{X}]$ and each term is divided by the lethal concentration of that toxicant $\left(\mathrm{LC}_{50, \mathrm{X}}\right)$; the individual contributions are summed to give the overall toxicity, described as the fractional effective dose (FED). When the sum exceeds 1.0, the effluent would be lethal to $50 \%$ of the exposed population. A more sophisticated approach recognises that incapacitation, rather than actual death, is the critical event in terms of fire safety. This has been defined in ISO 13571 [13] using consensus estimates of human response to toxicants. The measurements from the SSTF are suited to both approaches, but only the simpler rat lethality model is used here. Experimental toxic product yields can be normalised to a fixed mass/volume loading. In this work, a fuel mass-charge concentration of $20 \mathrm{~g} \mathrm{~m}^{-3}$ is used. This is equivalent to a fuel mass of $1 \mathrm{~kg}$ in a $50 \mathrm{~m}^{3} \mathrm{room}$.

$$
\begin{aligned}
& \mathrm{FED}=\left\{\frac{[\mathrm{CO}]}{\mathrm{LC}_{50, \mathrm{CO}}}+\frac{[\mathrm{HCN}]}{\mathrm{LC}_{50, \mathrm{HCN}}}+\frac{[\mathrm{HCl}]}{\mathrm{LC}_{50, \mathrm{HCl}}}+\frac{\left[\mathrm{NO}_{2}\right]}{\mathrm{LC}_{50, \mathrm{NO}_{2}}}+\ldots .+ \text { organics }\right\} \times \mathrm{V}_{\mathrm{CO}_{2}}+\mathrm{A}+\frac{21-\left[\mathrm{O}_{2}\right]}{21-5.4} \\
& \mathrm{~V}_{\mathrm{CO}_{2}}=1+\frac{\exp \left(0.14\left[\mathrm{CO}_{2}\right]\right)-1}{2}
\end{aligned}
$$

A is an acidosis factor equal to $\left[\mathrm{CO}_{2}\right] \times 0.05$.

Equation 2

\subsection{Toxic product yields of polyamide 6.6}

Previous reports $[3,14]$ of the fire toxicity of polyamide 6 have shown that combustion is efficient at low equivalence ratios with low yields of $\mathrm{CO}, \mathrm{HCN}$ and organics, all of which increase as the equivalence ratio exceeds 1 . The yields for $\mathrm{CO}$ and $\mathrm{HCN}$ increase with decrease in ventilation, or 
increase in $\phi$. In well-ventilated combustion conditions the CO yield was low, but increased steeply to a maximum of $0.32 \mathrm{~g} / \mathrm{g}$ at $\phi=2.3$. The yield of $\mathrm{HCN}$, another product of incomplete combustion, also increases with increasing $\phi$. The individual toxicant yields are shown in Figure 1 , as a function of equivalence ratio.

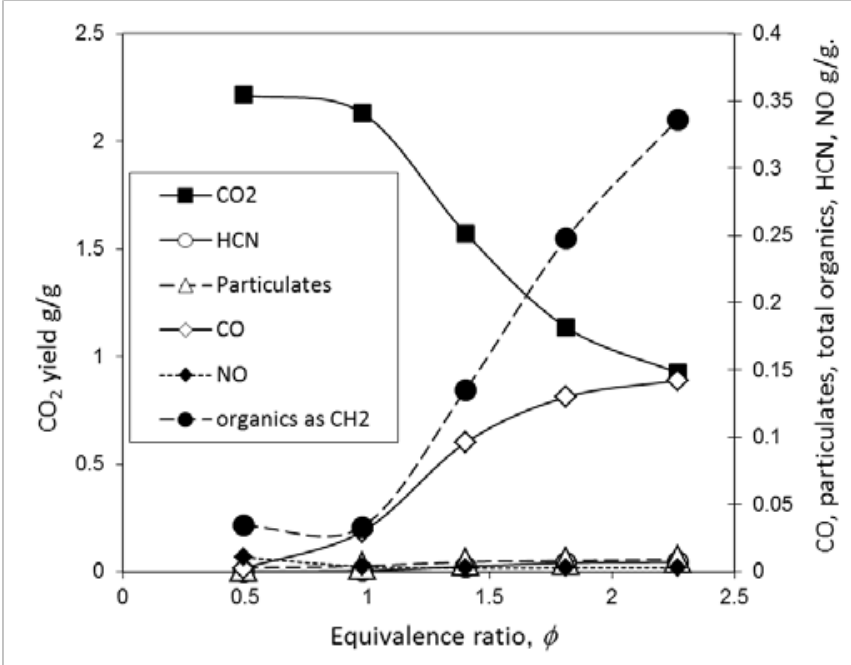

Figure 1 Yields of toxicants from burning polyamide 6, over the temperature range $650-825^{\circ} \mathrm{C}$

Equation 2 can be applied to toxic product yields, such as those shown in Figure 1, in order to predict the toxicity of the effluent. This shows that for polyamide 6 , the effluent toxicity and particularly the contribution of HCN grows significantly with under-ventilation, and increasing severity of fire. FED values of 6 or 8 may be interpreted as a polymer loading of $167 \mathrm{~g}$ or $125 \mathrm{~g}$, respectively, burning in a $50 \mathrm{~m}^{3}$ room, under the specified conditions, will be lethal to $50 \%$ of the occupying population in 30 minutes exposure. The contribution of each toxic species to the FED has been calculated, and is presented in Figure 2.

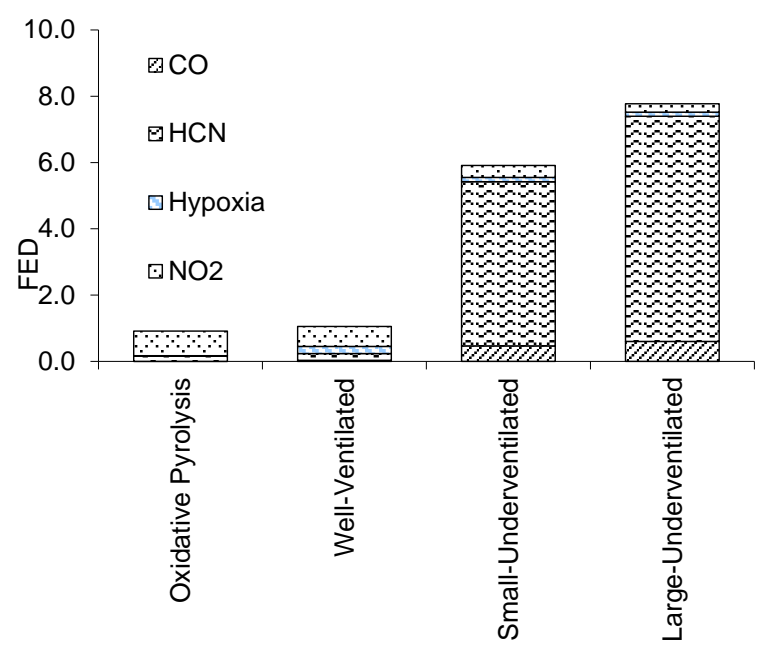

Figure 2 The contribution to toxicity of individual effluent components from polyamide 6 in different fire conditions

This shows that in well-ventilated conditions, $(\phi<1.0)$ the toxicity is low. For under-ventilated conditions $(\phi>1.0)$, the most significant contribution to the toxicity comes from $\mathrm{HCN}$. 


\subsection{Fire Hazards relating to electrical and electronic applications}

Glass reinforced polyamides are particularly common in electrical connectors and fuse boxes. The hazards presented by fire in electrical and electronic applications are rather different to those of larger or bulkier items, such as upholstered furniture or flammable insulation materials [15]. In the latter cases, once ignition occurs, fire growth will be rapid until it is controlled by the availability of oxygen, when it will continue to burn with $\phi>1$. In contrast, electrical and electronic components are at a higher risk of ignition due to the heating properties of electric currents, often under forced ventilation, but individual units tend to be smaller and better separated from other sources of fuel. Thus, while the under-ventilated fire is the most likely scenario for fire hazard assessment involving upholstered furniture, for a fuse box, or connector, it is more appropriate to focus on the fire toxicity in well-ventilated conditions.

\subsection{Flammability and fire toxicity regulation}

In Europe, the fire safety requirements for connectors and switches include IEC 60898 for circuit breakers, IEC 60947 for industrial control equipment and IEC 60335 for domestic appliances. The US Underwriters Laboratories (UL) standards have been widely adopted in Europe and Asia, as a material flammability classification test. UL $94 \mathrm{~V}-0$, for example, is probably the most commonly used requirement for reduced flammability across the globe.

The fire toxicity of components is specifically regulated in high risk applications, such as the mass transport industries (rail, air and sea), and in building regulations in China and Japan. In addition, performance based codes, used to produce a more holistic approach to fire safety, require quantification of available safe escape time (ASET) [13], before escaping is impeded by smoke, irritant gases or asphyxiants.

\subsection{Polyamide materials for electrical and electronic applications}

Polyamides are often chosen for electrical connectors and switch housings because of their toughness and rigidity. They are frequently reinforced with glass fibres to enhance their strength and dimensional stability. In connectors, polyamides permit the use of so-called "living hinges", thin plastics that can be flexed repeatedly without breaking; toughness is particularly important in snapfits for terminal blocks to allow easy assembly. Polyamides also have good heat-ageing properties, which is important because of the increasing temperatures due to miniaturization of electrical components and devices. However, these excellent mechanical properties are offset by fairly high flammability. Therefore, in many applications, a fire retardant must be added to the polymer.

\subsection{Fire retardation of polyamides}

The physical properties of glass fibre reinforced polyamides make them suitable for electrical devices with applications using high voltages. In polyamides, during burning, the glass fibre acts to stabilise the char [16]. However, regulatory requirements demand low flammability for materials in such applications. Flame retardants added to meet demanding requirements such as the UL-94 V-0 classification must not adversely affect the physical properties, or the durability of electrical components. Glass fibre reinforced polyamide 6 and 6.6 can be effectively flame retarded with 
halogenated flame retardants, such as brominated polystyrene, often used in combination with a synergist of antimony oxide, or with salts of organic phosphinic acids. The efficiency of dialkyl phosphinic acids as flame retardants in polyamides has been improved by synergism with melamine polyphosphate (MPP), achieving UL94 V-0 in glass filled polyamides [17]. The combination of diethyl aluminium phosphinate (AIPi) and MPP allows the loading in PA 6.6 to be reduced from $30 \%$ (for AIPi alone) to around $15-20 \%$, and still meet regulatory requirements, such as UL94 V-0 at thicknesses as low as $0.8 \mathrm{~mm}$ [16]. The mechanism of fire-retardant action of these phosphinic salts is considered in more detail in the discussion.

Halogenated flame retardants have a significant share of the market in reinforced polyamide mouldings, although competition from commercially available mixtures of the aluminium salt of diethyl phosphinate with melamine polyphosphate is growing.

\subsection{Drivers for the replacement of brominated flame retardants}

The development of halogen-free fire retardant systems has been driven by environmental arguments, which have had surprisingly little airing within the fire retardant polymer community, although we are all busy developing halogen-free fire retardant systems. Several halogenated flame retardants have been shown to be persistent and bioaccumulative, and are now ubiquitous throughout the built and natural environment $[18,19]$. A number of detailed studies have demonstrated the toxicity of these releases to humans and animals [20]. In 2010, a group of over 200 concerned scientists signed the San Antonio statement on brominated and chlorinated flame retardants [21] questioning their continued use and requesting urgent remedial action. The flame retardants currently causing concern are small molecules which can easily migrate through the polymer matrix, with consequent release into the environment. The brominated polystyrene used in this study is considered insufficiently mobile for release and transport in the environment. Further, there are now concerns over the fate of the halogen flame retardant synergist, antimony oxide, which has similar toxicity to arsenic oxides, with a threshold limit value of $0.5 \mathrm{mg} / \mathrm{m}^{3}$, in common with most antimony compounds [22]. Currently, (2013) though its high price (around $€ 10 \mathrm{~kg}^{-1}$ ) is also prompting searches for its replacement. Its persistence and toxicity mean that it is also considered a substance of environmental concern.

\section{Experimental}

\section{$2.1 \quad$ Sample preparation}

Six glass-reinforced polyamide materials were investigated, three based on polyamide 6 , and the other three on polyamide 6.6. For simplicity, these glass fibre composites will simply be referred to as PA 6 or PA 6.6. Each of these glass fibre composites was flame retarded using standard industry formulations containing either a blend of aluminium phosphinate and melamine polyphosphate (collectively abbreviated to AIPiM) or brominated polystyrene and antimony oxide (abbreviated to $\mathrm{BrSb})$. All the flame retardant samples were formulated to meet UL- $94 \mathrm{~V}-0$ at $0.8 \mathrm{~mm}$. In practice, this required a total flame retardant loading was lower for the PA/AIPiM materials than for the $\mathrm{PA} / \mathrm{BrSb}$ materials. The percentage by weight of each component is shown in Table 2. 
Compounds were prepared using a Leistritz ZSE 27 HP 44D twin screw extruder with a screw speed of $200 \mathrm{rpm}\left(20 \mathrm{~kg} \mathrm{~h}^{-1}\right)$. Extruded materials were water cooled and pelletized with a rotary cutter mill. The granulates were dried prior to being tested in the SSTF.

Table 2 Sample composition and abbreviated descriptor

\begin{tabular}{|l|c|c|c|c|c|c|}
\hline \multicolumn{1}{|r|}{ Descriptor } & & & & & & \\
Component & PA6 & PA6/AIPiM & PA6/BrSb & PA6.6 & PA6.6/AIPiM & PA6.6/BrSb \\
\hline PA 6 & 69.7 & 49.7 & 43.7 & & & \\
\hline PA 6.6 & & & & 69.7 & 49.7 & 43.7 \\
\hline Glass fibre & 30 & 30 & 30 & 30 & 30 & 30 \\
\hline Processing aid & 0.3 & 0.3 & 0.3 & 0.3 & 0.3 & 0.3 \\
\hline $\begin{array}{l}\text { Aluminium phosphinate/ } \\
\text { Melamine polyphosphate }\end{array}$ & & 20 & & & 20 & \\
\hline Brominated polystyrene & & & 20 & & & 20 \\
\hline Antimony trioxide & & & 6 & & & 6 \\
\hline
\end{tabular}

The product names (manufacturer) of the individual components are: PA 6, Durethan B29 (Lanxess); PA 6.6, Ultramid A27 (BASF); glass fibre, ESC-301CL (length $4.5 \mathrm{~mm}$, diameter $10 \mu \mathrm{m}$ ) (CIPC); aluminium phosphinate, Exolit OP 1230 (Clariant); melamine phosphate, Melapur 200/70 (BASF); brominated polystyrene, Saytex HP 3010G (Albemarle); Antimony Trioxide (as masterbatch in PA 6) 2617 (Campine); processing aid, Licowax E (Clariant).

\subsection{Steady state tube furnace apparatus (ISO/DIS 19700)}

The steady state tube furnace apparatus has been described elsewhere [11, 23], and is shown in Figure 3.

\section{Thermocouple}

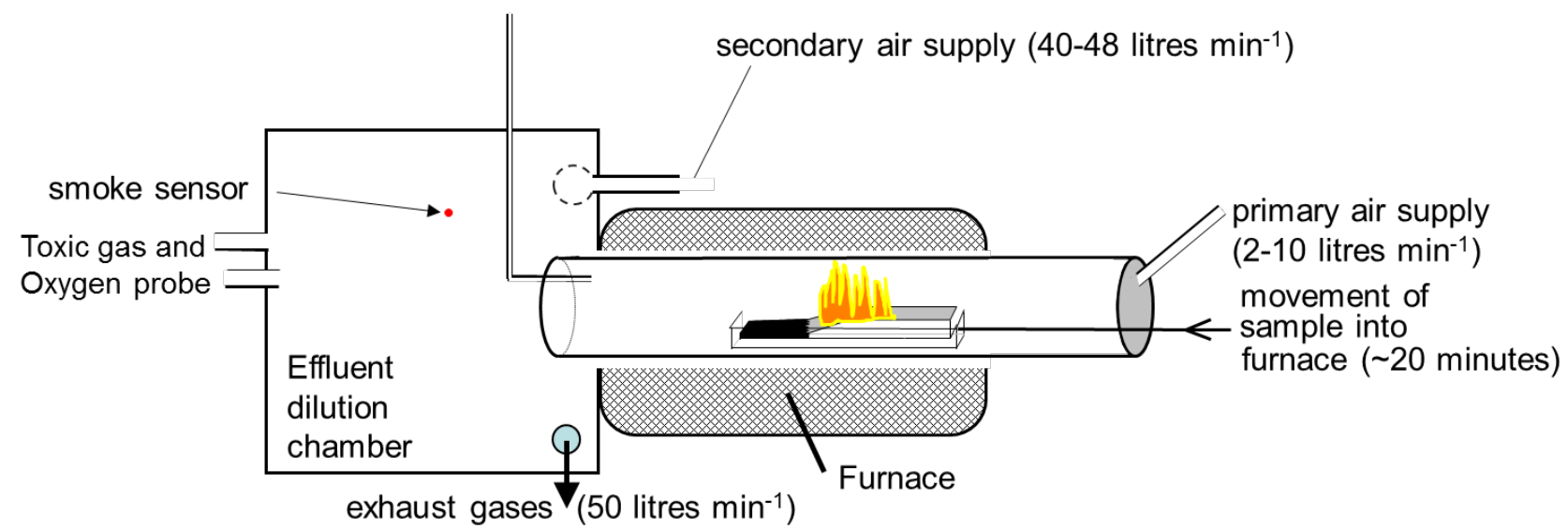

Figure 3 Diagram of the steady state tube furnace (ISO TS 19700)

The apparatus consists of a stationary tube furnace in which a quartz tube is fixed. Granules of the test specimen were placed in an $800 \mathrm{~mm}$ silica boat. During each experiment, the boat is driven into 
the furnace at a constant and controlled flow rate around $1 \mathrm{~g} \mathrm{~min}^{-1}$, typically over a period of about 20 minutes. A fixed flow of primary air passes through the tube furnace where it can react with the pyrolysing polymer, ignite and the gas phase fuel mix with all the available oxygen in the tube, and the resulting fumes pass into the effluent dilution chamber where it is mixed with a fixed and controlled secondary air supply. The secondary air increases the volume of analyte, and tends to keep the effluents from different ventilation conditions within the same analytical range. The requirement in each test run is to obtain a steady state of at least 5 minutes during which the concentrations of effluent gases and particulates can be measured, and flaming (or non-flaming) can be observed. For materials which do not burn completely, such as those containing noncombustible fillers, forming a char or leaving a residue, and those of unknown composition, the equivalence ratio can only be determined by calculating the oxygen depletion after the experiment. In this work, the primary air flow was varied with a fixed fuel feed rate in order to vary the equivalence ratio.

\section{Results}

The experiments were performed on granulated materials for a well-ventilated fire scenario at furnace temperatures of 650 and $850^{\circ} \mathrm{C}$. The actual equivalence ratio was obtained after subtraction of the mass of residue at the end of the experiment. This introduced a relatively small perturbation in the test conditions, which was not apparent until the end of the test (section 2.2). Carbon monoxide and carbon dioxide yields were measured together with hydrogen cyanide, nitrogen dioxide and hydrogen bromide. The yields are all expressed on a mass-charge basis, and yields and measured equivalence ratios from comparable runs are presented individually, showing the actual values of the equivalence ratio.

\subsection{Polyamide 6}

The yields of carbon dioxide, carbon monoxide, hydrogen cyanide and nitrogen dioxide are presented for each polyamide as representative of the toxicants present. For the two materials containing bromine (PA 6/BrSb and PA 6.6/BrSb), data on $\mathrm{HBr}$ yields is presented at the end of the section on Polyamide 6.6. Only one result was obtained for well-ventilated conditions for $\mathrm{PA} 6 / \mathrm{BrSb}$ at $650^{\circ} \mathrm{C}$, but results are also shown for $\phi$ values around 1 , which suggest similar trends with the single exception of the $\mathrm{HCN}$ yield for $\mathrm{PA} 6 / \mathrm{BrSb}$ at $650^{\circ} \mathrm{C}$ 


\subsubsection{Carbon dioxide yields}

Figure 4 shows the variation in carbon dioxide yields for the three polyamide 6/glass fibre based materials. This can be related to the combustion efficiency. The theoretical maximum $\mathrm{CO}_{2}$ yield from complete combustion of PA 6 containing $30 \%$ glass fibres is $1.64 \mathrm{~g} \mathrm{CO}_{2}$ per $\mathrm{g}$ of material. Thus the PA 6 is burning with around $85 \%$ combustion efficiency at $650{ }^{\circ} \mathrm{C}$ and, surprisingly, around $80 \%$ at $825^{\circ} \mathrm{C}$. The PA 6 sample flame retarded with aluminium phosphinate and melamine polyphosphate (PA 6/AIPiM) has a theoretical yield of $1.4 \mathrm{~g} \mathrm{CO}_{2}$ per $\mathrm{g}$ of material, showing a disproportionately lower $\mathrm{CO}_{2}$ yield than $\mathrm{PA} 6$, indicating both the lower carbon content, and a reduced combustion efficiency, indicative of gas phase inhibition. There is little difference between the yields at $650{ }^{\circ} \mathrm{C}$ and $825^{\circ} \mathrm{C}$. The PA 6 sample flame retarded with brominated polystyrene and antimony trioxide (PA 6/BrSb) with a theoretical yield of $1.3 \mathrm{~g} \mathrm{CO}_{2}$ per $\mathrm{g}$ of material, shows lower combustion efficiency and hence considerable gas phase inhibition at $650{ }^{\circ} \mathrm{C}$, though the combustion efficiency increases noticeably at $825^{\circ} \mathrm{C}$.

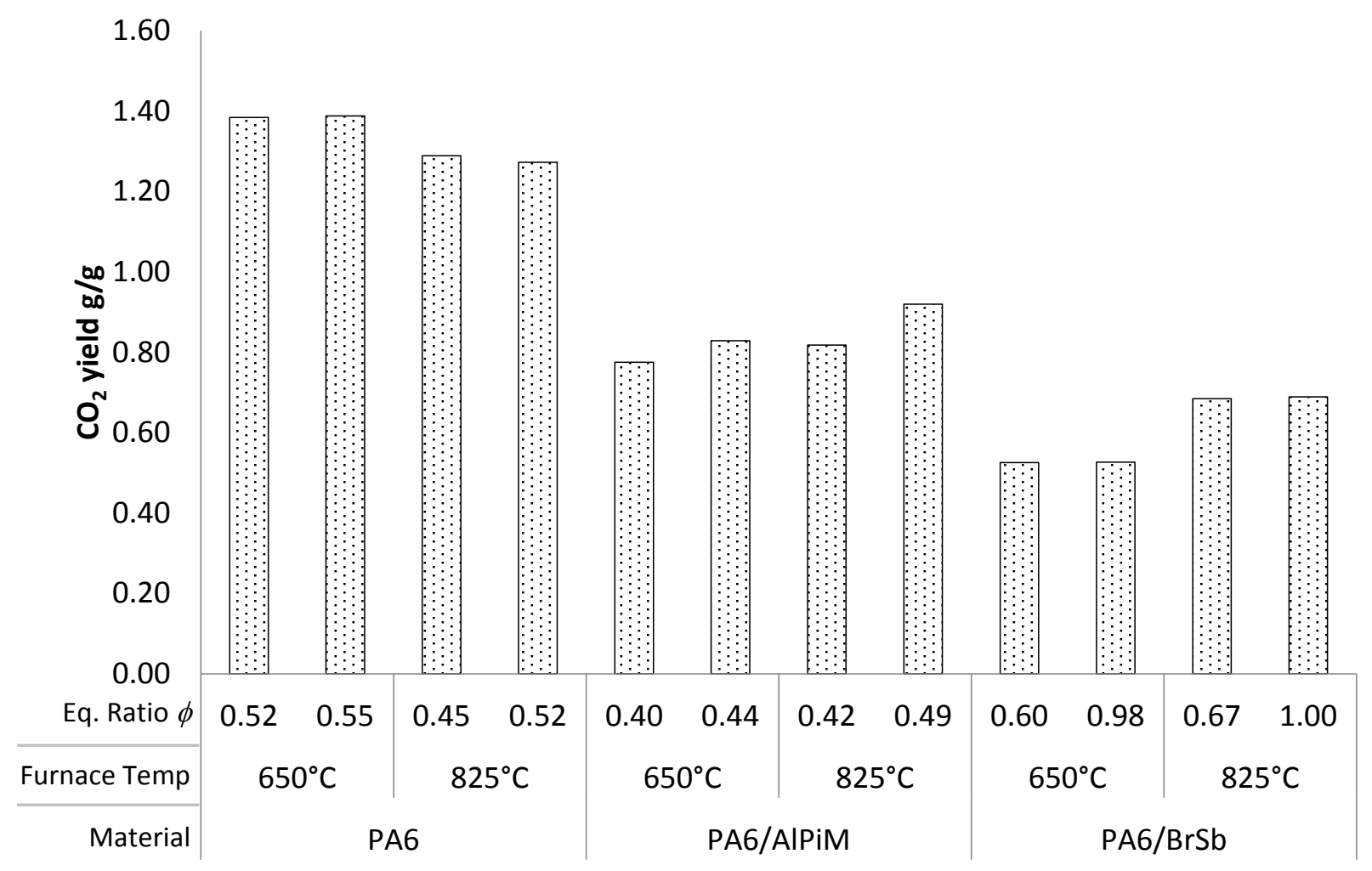

Figure 4 Carbon dioxide yields from PA 6 based materials 


\subsubsection{Carbon monoxide yields}

As well as being a toxicant in its own right, carbon monoxide is generally considered a good indicator of incomplete combustion. Thus if the $\mathrm{CO}$ yield is high, it is likely that the yields of the other toxic products will also be higher. Figure 5 shows the CO yields from PA 6 materials. PA 6 shows low CO yields at both 650 and $825^{\circ} \mathrm{C}$. In contrast, PA 6/AIPiM shows elevated $\mathrm{CO}$ yields at $650{ }^{\circ} \mathrm{C}$, which are not observed for the same material burnt at $825^{\circ} \mathrm{C}$, suggesting gas phase inhibition occurs at $650{ }^{\circ} \mathrm{C}$, but is "switched off" at $825^{\circ} \mathrm{C}$. The slight increase in $\mathrm{CO}_{2}$ yields at $825^{\circ} \mathrm{C}$ is more than sufficient to account for this change. For the PA $6 / \mathrm{BrSb}$ material, the $\mathrm{CO}$ yield is very high, particularly at $650{ }^{\circ} \mathrm{C}$, though in both cases only showing a small increase with increase in $\phi$. Given the lower fuel content of PA 6/BrSb (containing both GF, brominated polystyrene and antimony oxide) this yield, per $\mathrm{g}$ of PA 6, is higher than that for pure polyamide 6 (Figure 1 ) under the most toxic, underventilated conditions. This shows gas phase inhibition of the conversion of $\mathrm{CO}$ to $\mathrm{CO}_{2}$, which is not sensitive to temperature over the range considered.

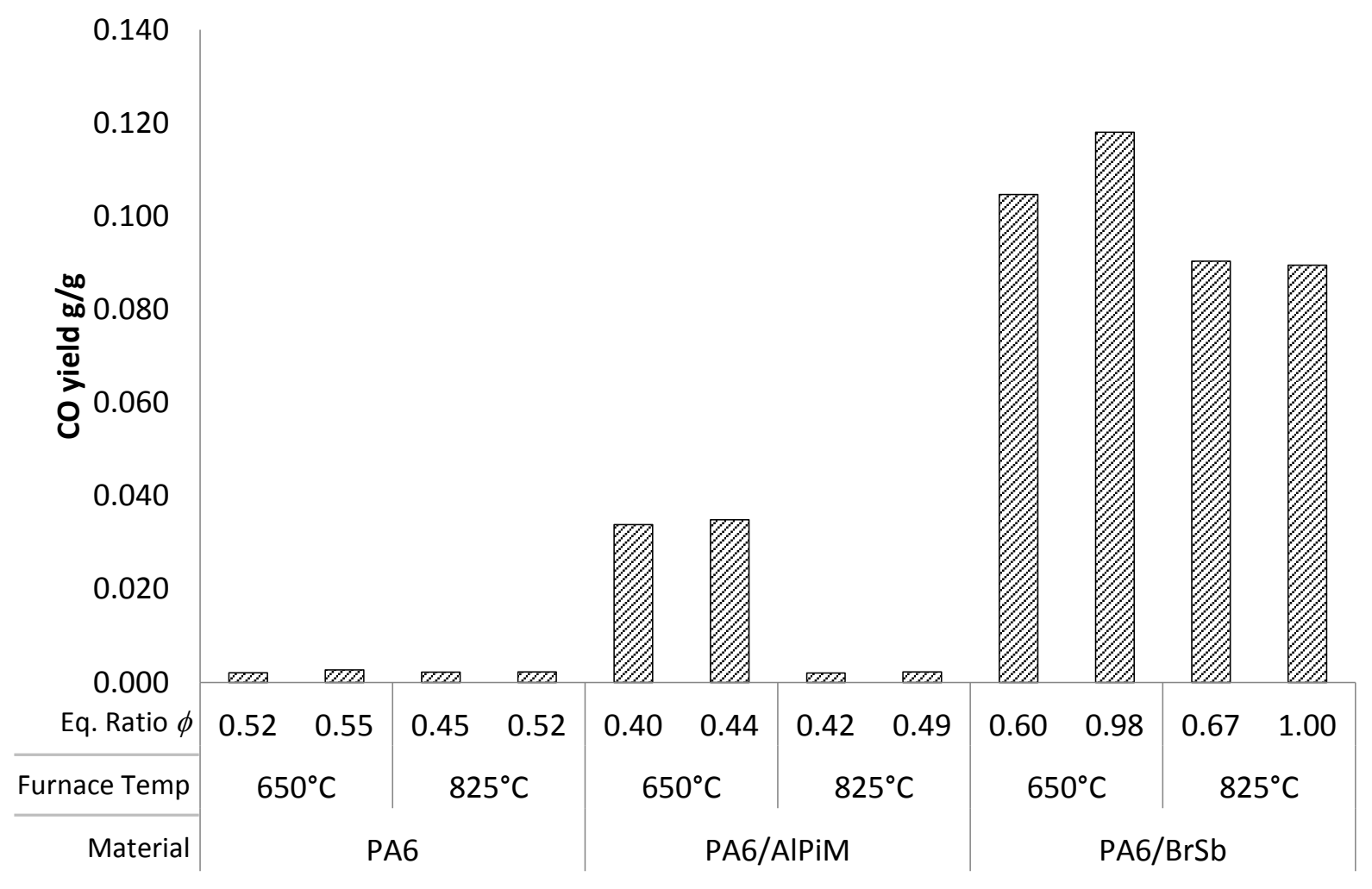

Figure 5 Carbon monoxide yields from PA 6 based materials 


\subsubsection{Hydrogen cyanide yields}

The hydrogen cyanide yields for a related polymer, polyamide 6.6 are described in the introduction, and only show significant yields in under-ventilated conditions. Figure 6 shows the HCN yields for the three PA 6 materials. It can be seen that very low, but measurable yields of $\mathrm{HCN}$ are observed for PA 6 with glass fibre. As the furnace temperature increases from 650 to $825^{\circ} \mathrm{C}$, there is a noticeable decrease in the $\mathrm{HCN}$ yield, showing more complete oxidation. A higher $\mathrm{HCN}$ yield is observed for the PA 6/AIPiM material, indicative of gas phase inhibition, which switches off at $825^{\circ} \mathrm{C}$, when the HCN yield falls by over $50 \%$. In contrast, the $\mathrm{HCN}$ yield from the PA 6/BrSb material is around a factor of 20 greater than that for PA 6, and around a factor of 5 greater than that from PA 6/AIPiM. In addition, at the lower furnace temperature, the $\mathrm{HCN}$ yield is more strongly dependent on equivalence ratio, whereas at the higher temperature, it is almost independent of equivalence ratio. Most notably, in well-ventilated conditions, when little HCN is produced by non-flame retardant polyamides, the material containing $\mathrm{BrSb}$ shows the highest $\mathrm{CO}$ and $\mathrm{HCN}$ yields of any of those tested.

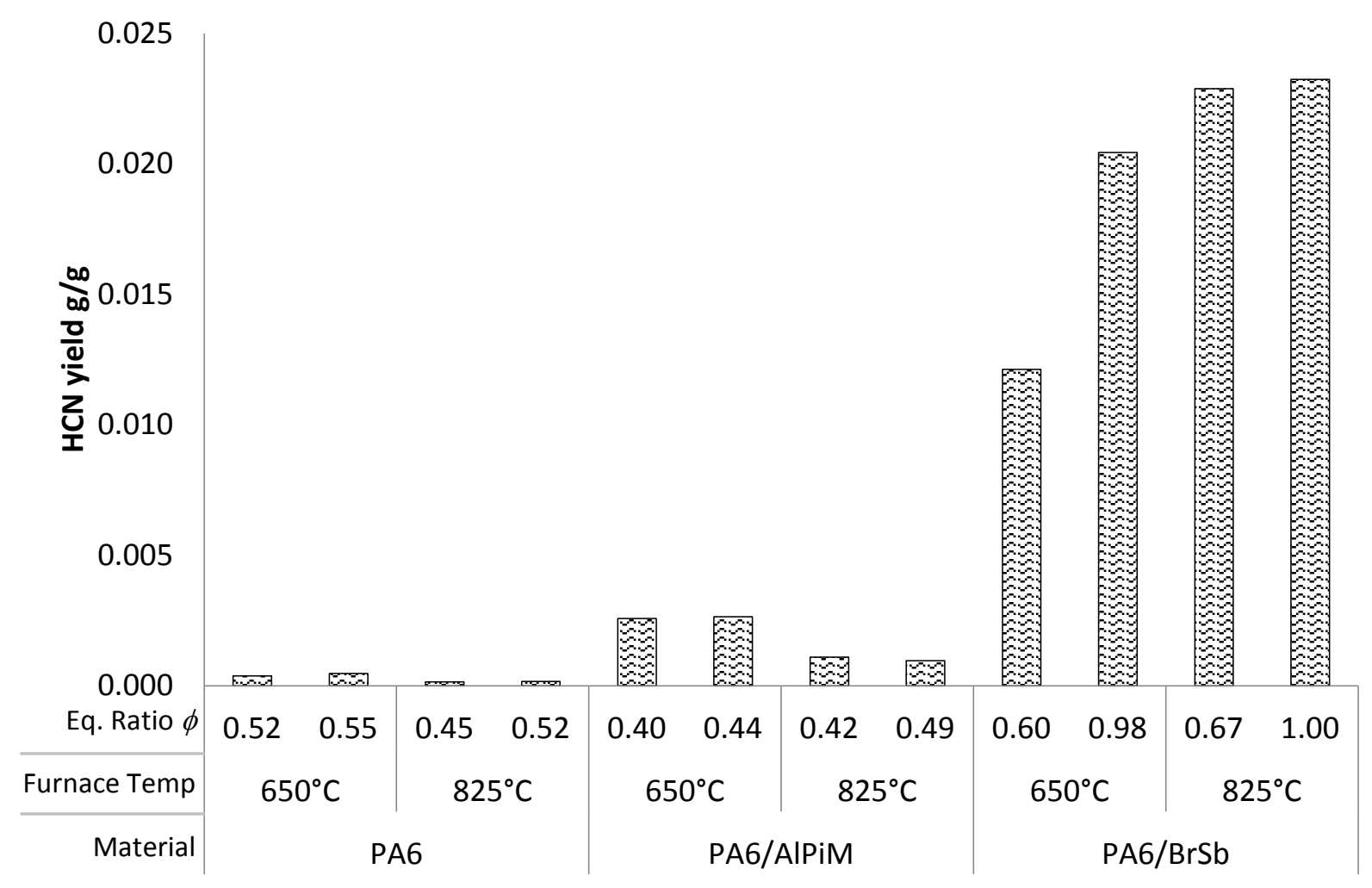

Figure 6 Hydrogen cyanide yields from PA 6 based materials 


\subsubsection{Nitrogen dioxide yields}

Very low yields of nitrogen dioxide were found during combustion of the PA 6 based materials. The $\mathrm{NO}_{2}$ detected is close to the limits of detection and quantification. Figure 7 shows the variation of $\mathrm{NO}_{2}$ yields for the three PA 6 materials. There seems to be a progressive increase in $\mathrm{NO}_{2}$ yields with gas phase inhibition, surprisingly showing a similar trend to the $\mathrm{CO}$ and $\mathrm{HCN}$ yields.

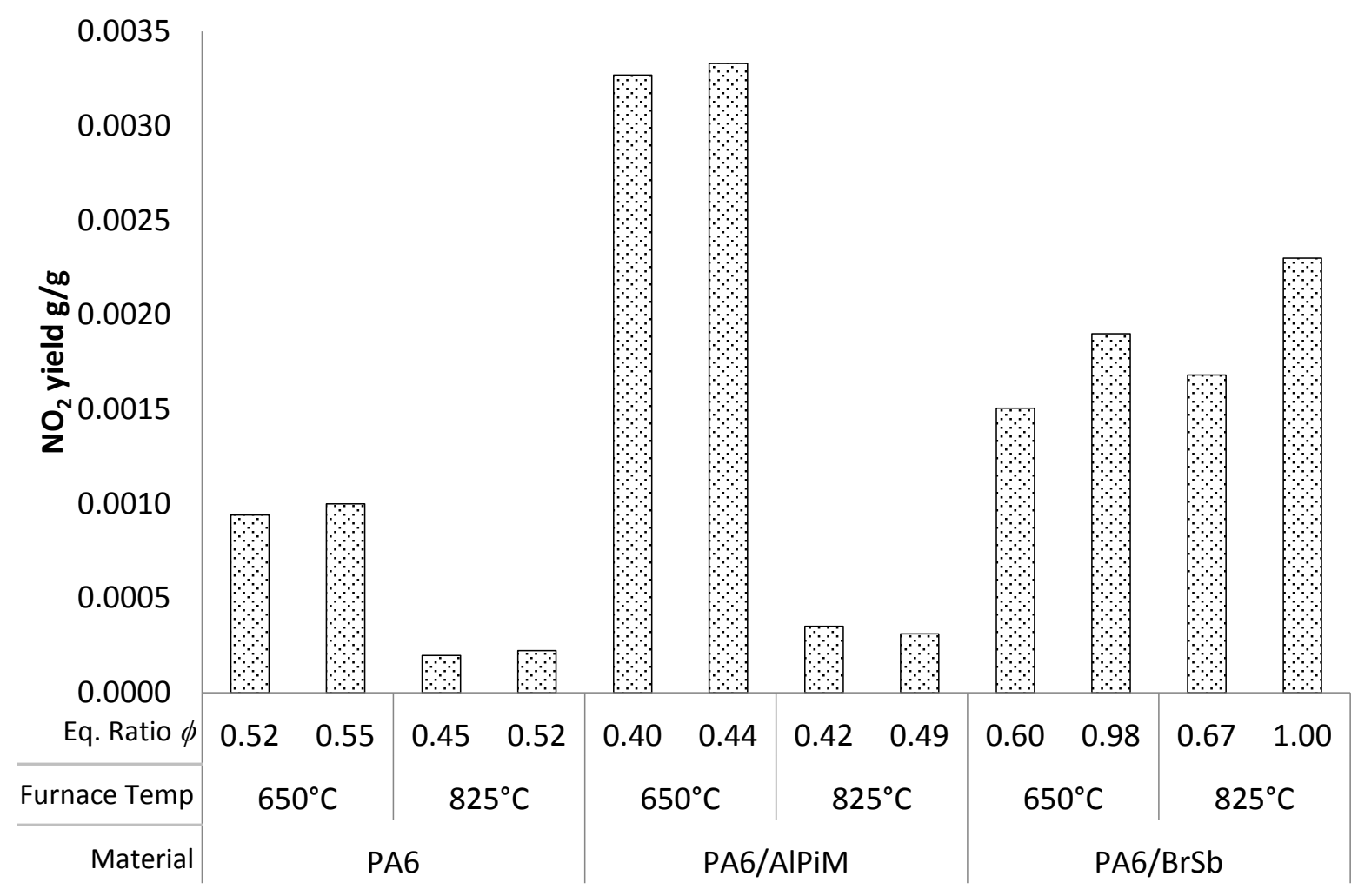

Figure $7 \mathrm{NO}_{2}$ yields from PA 6 based materials 


\subsection{Polyamide 6.6}

The results for glass-reinforced polyamide 6.6 based materials show similar trends to those observed for PA 6.

\subsubsection{Carbon dioxide yields}

The theoretical yield of $\mathrm{CO}_{2}$ for complete combustion of PA 6.6 containing $30 \%$ glass fibre is $1.57 \mathrm{~g} / \mathrm{g}$. The measured yields, shown in Figure 8, are similar to those for PA 6, showing high combustion efficiency. For PA 6.6/AIPiM, with a theoretical yield of $1.33 \mathrm{~g} \mathrm{CO}_{2}$ per $\mathrm{g}$ of material burnt, the lower combustion efficiency observed at $650{ }^{\circ} \mathrm{C}$ is less evident at $825^{\circ} \mathrm{C}$. For PA 6.6/BrSb, with a theoretical yield of $1.26 \mathrm{~g} \mathrm{CO}_{2}$, a very low combustion efficiency is observed at $650{ }^{\circ} \mathrm{C}$, which shows only a small increase at $825^{\circ} \mathrm{C}$, suggesting the antimony-bromine combination is a more efficient gas phase inhibitor for PA 6.6 than for PA 6.

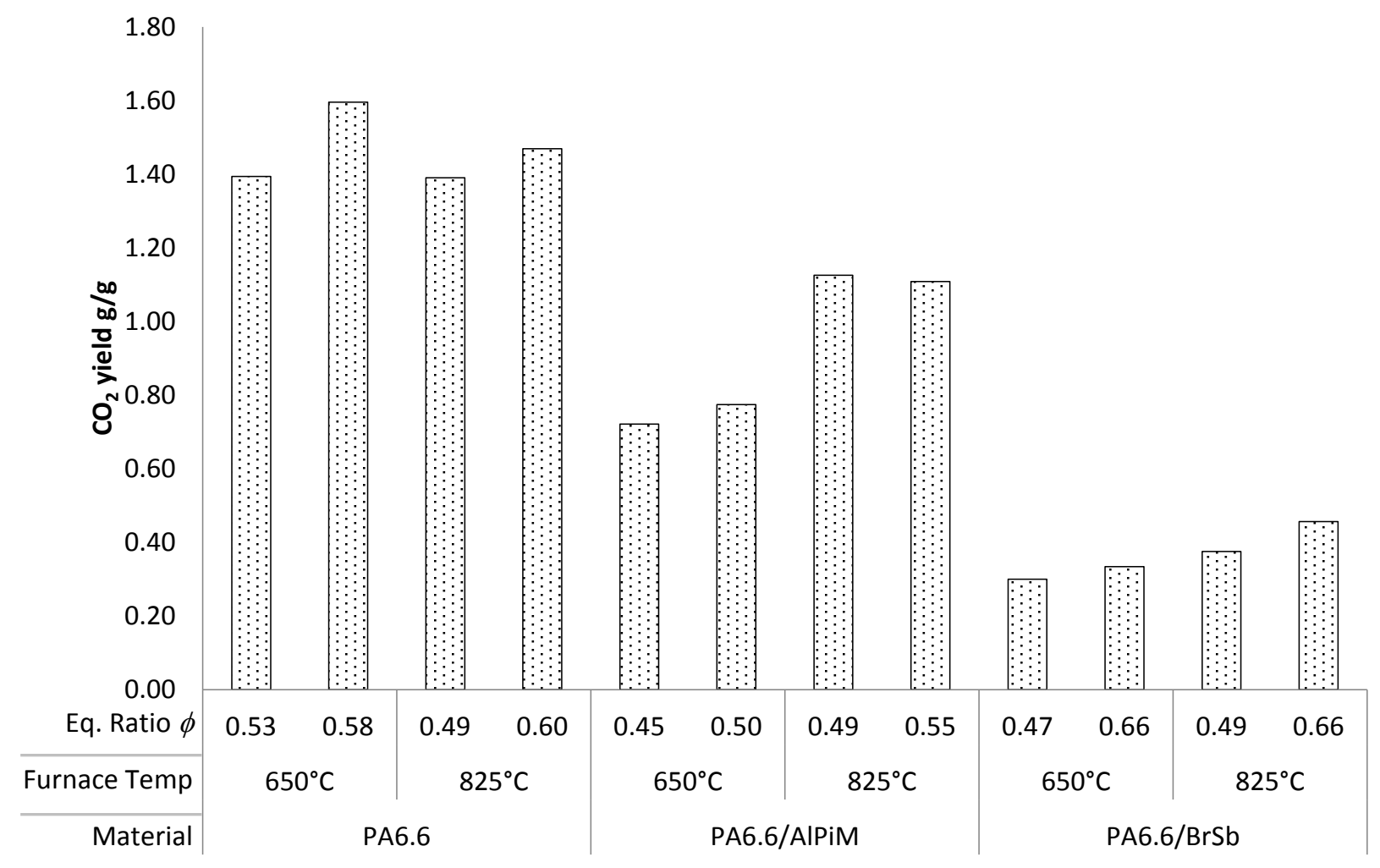

Figure 8 Carbon dioxide yields from PA 6.6 based materials 


\subsubsection{Carbon monoxide yields}

The $\mathrm{CO}$ yields for PA 6.6 based materials are shown in Figure 9. PA 6.6 alone shows low CO yields, confirming the high combustion efficiency at both 650 and $825^{\circ} \mathrm{C}$ observed for the $\mathrm{CO}_{2}$ yields. For PA 6.6/AIPiM, similar behaviour is observed to the PA 6/AIPiM material, except that the difference between the two furnace temperature settings appears to be even greater. At $650^{\circ} \mathrm{C}$, the $\mathrm{CO}$ yield is higher for PA 6.6 than for PA 6, while at $825^{\circ} \mathrm{C}$, it is lower. More noticeable is the dramatic increase in $\mathrm{CO}$ yield at both 650 and $825^{\circ} \mathrm{C}$ for the PA 6/BrSb material.

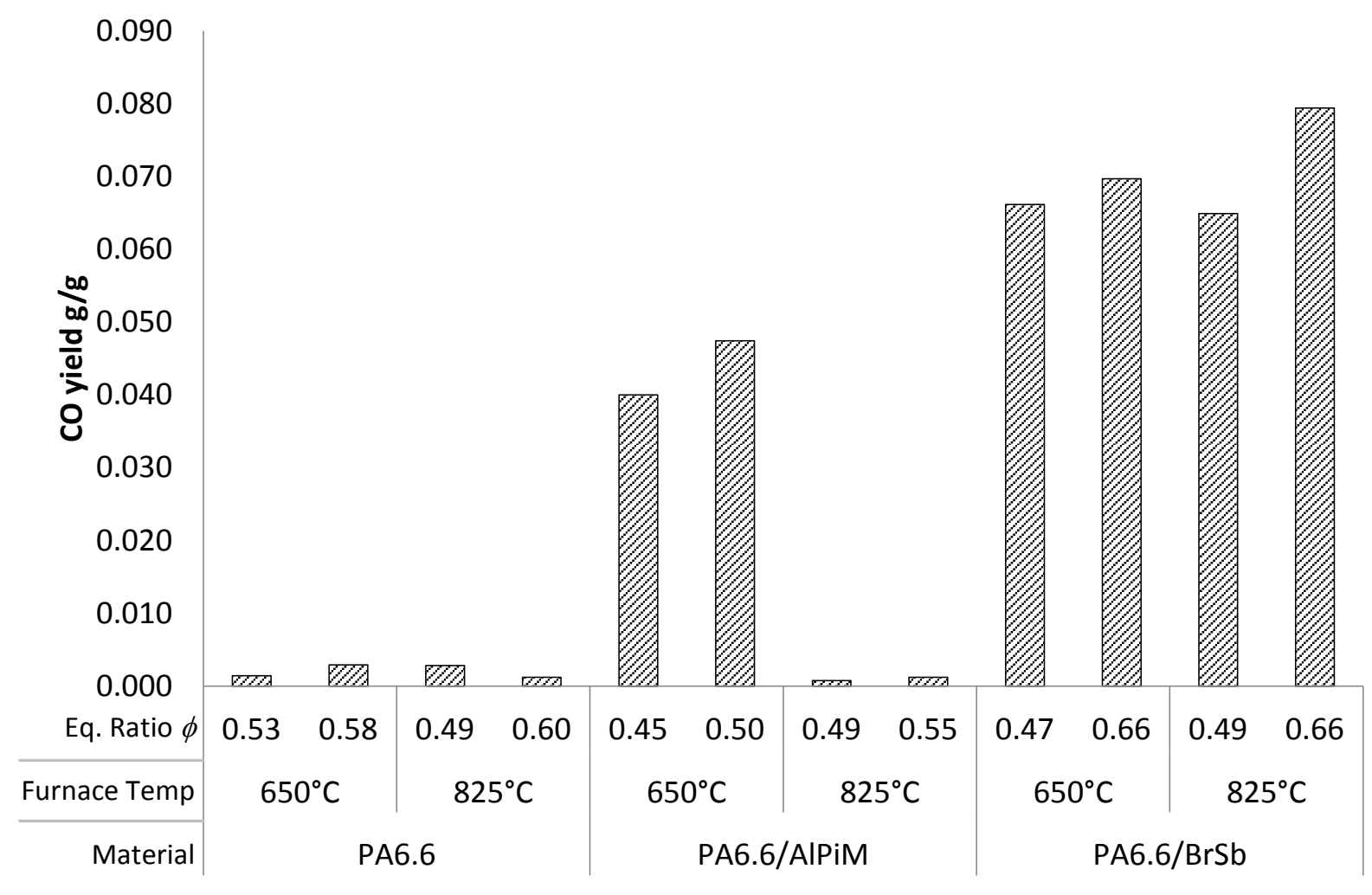

Figure 9 Carbon monoxide yields from PA 6.6 based materials 


\subsubsection{Hydrogen cyanide yields}

The HCN yields for PA 6.6 based materials are shown in Figure 10. For PA 6.6 and PA 6.6/AIPiM, these show a similar trend to those for $\mathrm{CO}$, in that the PA 6.6 yields are very low, and the PA 6.6/AlPiM yields decrease from 650 to $825^{\circ} \mathrm{C}$. The $\mathrm{HCN}$ yields from the PA 6.6/BrSb material are very high yield for burning in well-ventilated conditions. Moreover, as observed for the $\mathrm{CO}$ yield for the PA 6.6/BrSb, there appears to be a slight increase in the HCN yield (and hence the inhibitory effects of brominated polystyrene and antimony oxide) at $825^{\circ} \mathrm{C}$.

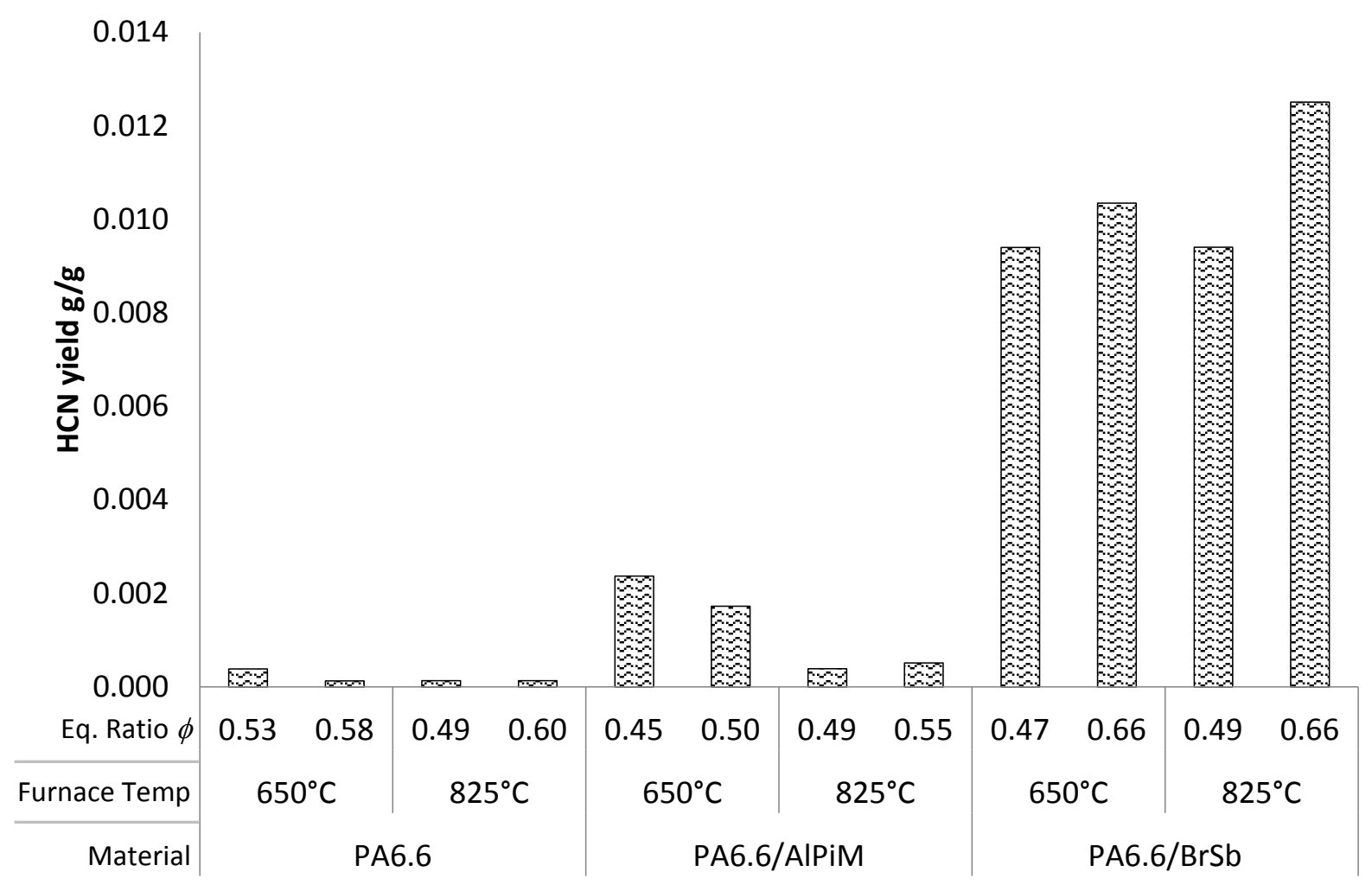

Figure 10 Hydrogen cyanide yields from PA 6.6 based materials 


\subsubsection{Nitrogen dioxide yields}

Figure 11 shows the $\mathrm{NO}_{2}$ yields for $\mathrm{PA} 6.6$ based materials. Again all the yields are close to the limits of detection and quantification, though higher than those for PA 6. Similar to PA 6 materials, the highest $\mathrm{NO}_{2}$ yields are found for PA 6. 6/AIPiM materials burnt in the furnace at $650{ }^{\circ} \mathrm{C}$. A similar, but smaller trend of $\mathrm{NO} 2$ formation being favoured at lower furnace temperatures appears to be evident from the PA 6.6/BrSb materials burnt at the lower temperature in the more well-ventilated condition of $\phi=0.47$.

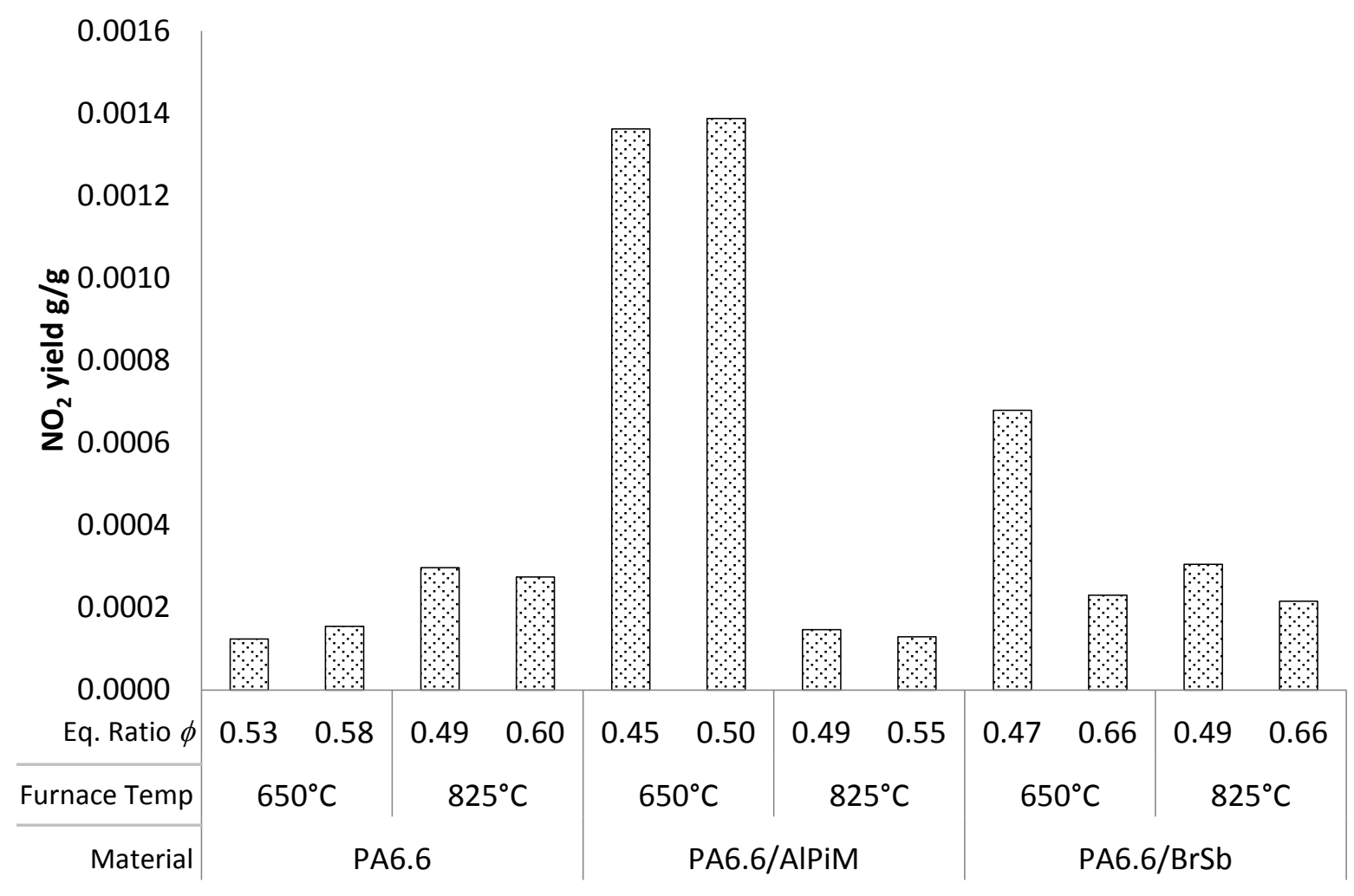

Figure $11 \mathrm{NO}_{2}$ yields from PA 6.6 based materials 


\subsubsection{Hydrogen bromide yields from PA 6/BrSb and PA 6.6/BrSb}

Figure 12 shows the measured yield of hydrogen bromide $(\mathrm{HBr})$ from the materials containing the brominated polystyrene flame retardant. The theoretical yield of $\mathrm{HBr}$ is around $0.14 \mathrm{~g} / \mathrm{g}$. The maximum recovery of bromine as $\mathrm{HBr}$ is thus only around $25 \%$ this. This probably arises from the readiness of acid gases to attach themselves to exposed metal surfaces, water droplets and soot particles, and may represent an underestimate of the quantities of $\mathrm{HBr}$ that may be encountered in the effluent from a real fire. Alternatively, more bromine may be present in organic form, rather than as $\mathrm{HBr}$, although the high yields of $\mathrm{CO}$, in particular, also suggest a higher concentration of $\mathrm{HBr}$ than those detected, since $\mathrm{HBr}$ inhibits the conversion of $\mathrm{CO}$ to $\mathrm{CO}_{2}$, by reducing the $\cdot \mathrm{OH}$ concentration.

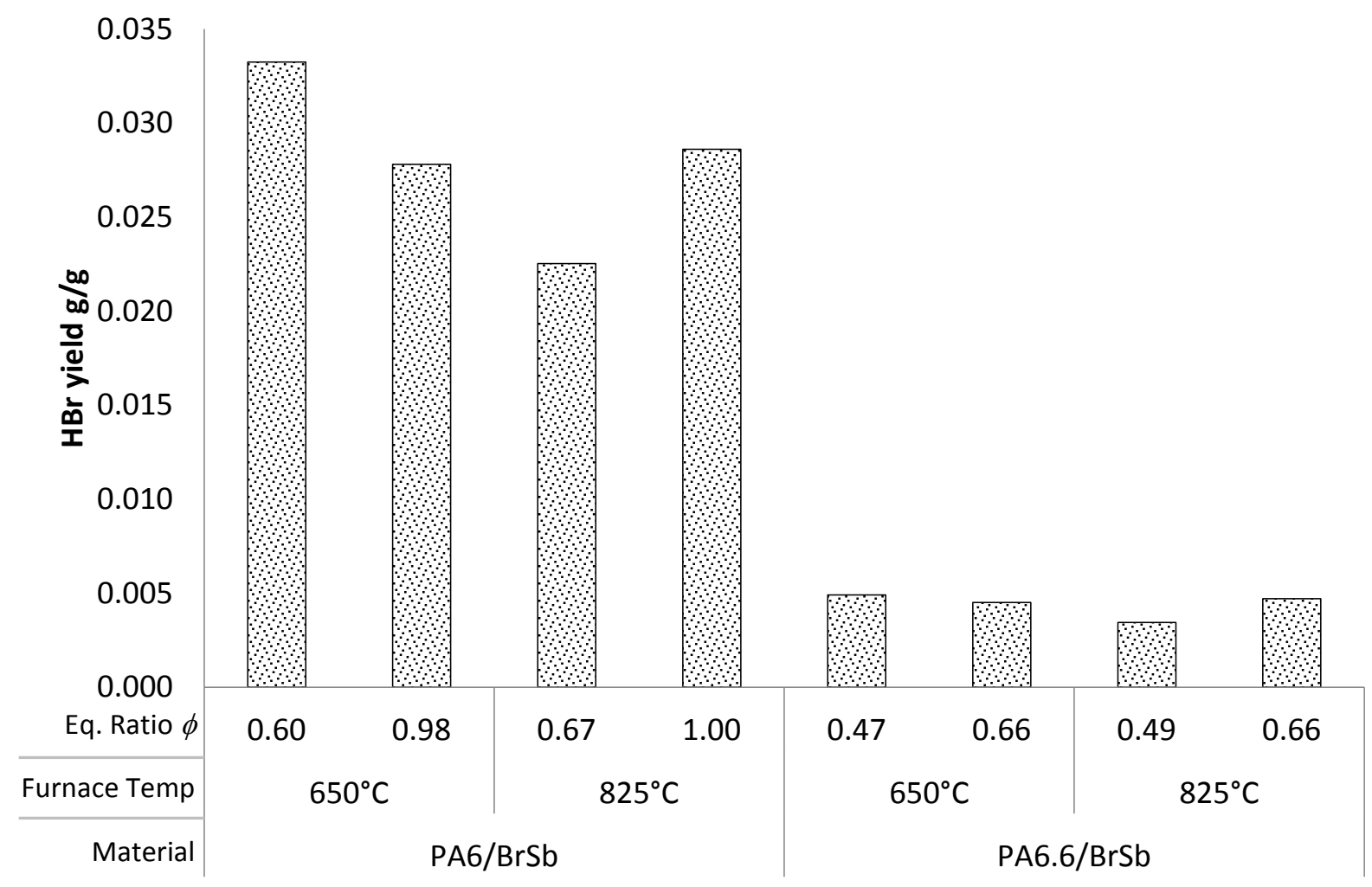

Figure $12 \mathrm{HBr}$ yields from materials containing bromine 


\section{Discussion}

This work has shown that in aliphatic polyamides, brominated flame retardants with an antimony oxide synergist, which interfere with gas-phase free radical reactions, produce high yields of both carbon monoxide and hydrogen cyanide. In contrast, the aluminium phosphinate/melamine polyphosphate combination, which is believed to act in both gas and condensed phases, causes a significantly smaller increase in the yields of these two main asphyxiants. These yields may be expressed in terms of estimates of effluent toxicity.

\subsection{Estimation of contribution to toxicity of individual components in the fire effluent}

Figure 13 shows how the individual yields may be translated into estimates of toxicity expressed as fractional effective dose (FED), (at an arbitrary loading of $1 \mathrm{~kg}$ of material in $50 \mathrm{~m}^{3}$ ). Even at this high loading, many of the material/conditions show FEDs well below the critical value of 1 (representing lethality to $50 \%$ of the population during a 30 minute exposure. The two exceptions are the materials containing AIPiM, when burning at the lower furnace temperature of $650^{\circ} \mathrm{C}$, and the materials containing $\mathrm{BrSb}$ at both furnace temperatures. In each case, where the FEDs exceed one, the major contribution to the toxicity comes from hydrogen cyanide, with smaller contribution from carbon monoxide at about $1 / 5^{\text {th }}$ of the $\mathrm{HCN}$ level. There is also a minor contribution from $\mathrm{NO}_{2}$ from all materials, in all fire conditions. It is notable that the fire toxicity of the PA 6/BrSb materials is a factor of 10 larger than that of PA 6 and a factor of 5 larger than the AIPiM material at $650^{\circ} \mathrm{C}$; at $825^{\circ} \mathrm{C}$ it is a factor of 30 larger than the PA 6, and 17 larger than the AlPiM material. The BrSb materials all show high fire toxicity under the normally least toxic, well-ventilated fire conditions. The lower fire toxicity of the AIPiM materials at higher temperatures suggest a reduction in fire hazard. It is well known that under more severe conditions than a small flame ignition test, flame retarded materials will burn, and frequently produce more toxic effluents as a result of quenching of the gas phase flame reactions. It appears that the AlPiM system switches off this flame quenching process as the fire becomes more severe, reducing the toxicity of the effluent. These surprising findings led to the detailed investigation of the chemistry of the processes, which are discussed in more detail in 4.2 . 


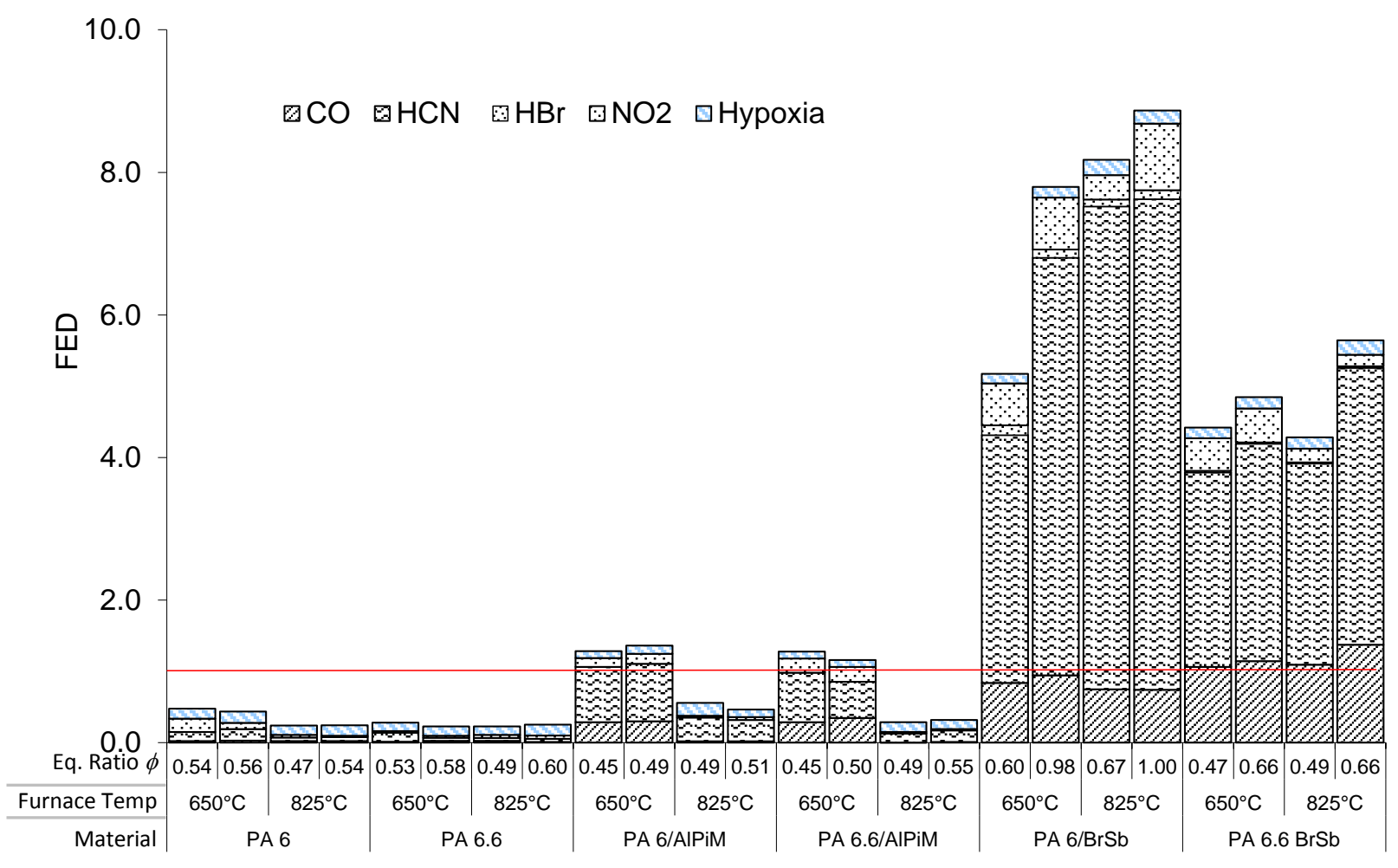

Figure 13 Contributions to effluent toxicity from PA 6 and PA 6.6 based materials

These estimates of toxicity can be expressed in terms of fire safe limits on combustible loadings in enclosures. The $\mathrm{LC}_{50}$ concept may also be applied to materials burning under specified conditions. In this case, the $\mathrm{LC}_{50}$ is related to the FED by Equation 3 [12].

$$
L C_{50}=\frac{m}{V \times F E D}
$$

Equation 3

Thus for the base polymers with glass fibre reinforcement, and for the four comparably flame retarded samples, an $\mathrm{LC}_{50}$ may be calculated (

Table 3).

Table $3 L^{L} C_{50}$ for each material and furnace temperature (the mass required to generate a lethal effluent in grams per cubic metre)

\begin{tabular}{|l|c|c|}
\cline { 2 - 3 } \multicolumn{1}{c|}{} & \multicolumn{2}{c|}{ Furnace Temperature $/{ }^{\circ} \mathbf{C}$} \\
\hline Sample & $\mathbf{6 5 0}$ & $\mathbf{8 2 5}$ \\
\hline PA 6 & 44 & 83 \\
\hline PA 6/AIPiM & 15 & 40 \\
\hline PA 6/BrSb & 3.3 & 2.4 \\
\hline PA 6.6 & 80 & 84 \\
\hline PA 6.6/AIPiM & 16 & 66 \\
\hline
\end{tabular}




\begin{tabular}{|l|l|l|}
\hline PA 6.6/BrSb & 4.3 & 4.1 \\
\hline
\end{tabular}

The $\mathrm{LC}_{50}$ is inversely proportional to the toxicity (higher values indicate lower toxicity). If the mass of material equal to the $\mathrm{LC}_{50}$ is burnt in well-ventilated conditions, this would be fatal to $50 \%$ of the occupying population. Therefore, if a $1 \mathrm{~kg}$ fuse box made of glass reinforced polyamide 6 , flame retarded to UL94 V-0 with brominated polystyrene and antimony oxide, was to burn completely in conditions corresponding to a small, well-ventilated fire $\left(650^{\circ} \mathrm{C}\right)$ it would generate a volume of lethal effluent of $300 \mathrm{~m}^{3}$ (for 30 min exposure), whereas if it were flame retarded with AIPiM it would only generate a volume of lethal effluent of $67 \mathrm{~m}^{3}$ under the same conditions. Fire safety engineers would generally apply a safety margin, for example that the FED could not exceed 0.3 , to ensure that the fire effluent would not be lethal to the occupying population.

\subsection{Gas phase flame retardant mechanisms}

Both carbon monoxide and hydrogen cyanide are formed in the flames of burning polyamides (and other polymers containing $\mathrm{C}$ and $\mathrm{N}$ ). The effects of brominated and phosphinate flame retardants on these processes are considered, in order to explain why the AIPiM flame retardant had a lesser effect on the yields of $\mathrm{CO}$ and $\mathrm{HCN}$, and their sensitivity to furnace temperature.

\subsection{Flame retardant mechanism of antimony-bromine systems}

Flaming combustion involves a complex set of reactions between a very small number of highly reactive free radicals. For ignition to occur, the number of radicals must exceed a small, but critical concentration. In reactions 1 and 2, each "." represents an unpaired electron; overall, the reaction of a single $\mathrm{H}$ - radical with molecular oxygen results in the formation of three radicals. This is the "chainbranching" step fundamental to all flaming reactions.

$$
\begin{aligned}
& \mathrm{H} \cdot+\mathrm{O}_{2} \leftrightarrows \quad \mathrm{OH}+\cdot \mathrm{O} \cdot \\
& \cdot \mathrm{O}+\mathrm{H}_{2} \leftrightarrows \quad \mathrm{OH}+\mathrm{H} \cdot
\end{aligned}
$$

Once sufficient radicals have been formed, their concentration needs to be maintained for flaming combustion to continue. In the gas phase, brominated flame retardants act by releasing hydrogen bromide $(\mathrm{HBr})$ during thermal decomposition, which interferes with the flame processes. During polymer decomposition, the flame retardant (such as brominated polystyrene) breaks down.

$$
\mathrm{ArBr} \rightarrow \mathrm{Ar} \cdot+\mathrm{Br} .
$$

The bromine radical abstracts $\mathrm{H}$. from a fuel molecule to form $\mathrm{HBr}$ :

$$
\mathrm{Br} \cdot+\mathrm{RH} \leftrightarrows \mathrm{R} \cdot+\mathrm{HBr}
$$

which in turn interferes with the radical chain mechanism:

$$
\begin{aligned}
& \mathrm{HBr}+\mathrm{H} \cdot \leftrightarrows \mathrm{H}_{2}+\mathrm{Br} . \\
& \mathrm{HBr}+\cdot \mathrm{OH} \leftrightarrows \mathrm{H}_{2} \mathrm{O}+\mathrm{Br} .
\end{aligned}
$$


Thus the high-energy $\mathrm{OH} \cdot$ and $\mathrm{H} \cdot$ radicals formed by chain branching are removed by the $\mathrm{HBr}$. The removal of $\mathrm{H}$. is key to elimination of the main chain branching steps ( 1 and 2) (when 1 radical becomes 3 radicals), preventing the formation of $2 \cdot \mathrm{OH}$ radicals. Collision with a third body, $\mathrm{M}$, results in termination processes, and crucially, recycling of $\mathrm{HBr}$.

$$
\begin{aligned}
& \mathrm{Br} \cdot \mathrm{Br} \cdot+\mathrm{M} \leftrightarrows \mathrm{Br}_{2}+\mathrm{M} \\
& \mathrm{H} \cdot+\mathrm{Br} \cdot+\mathrm{M} \leftrightarrows \mathrm{HBr}+\mathrm{M} \\
& \mathrm{H} \cdot+\mathrm{Br}_{2} \leftrightarrows \mathrm{HBr}+\mathrm{Br} \cdot
\end{aligned}
$$

Thus $\mathrm{HBr}$ is a catalyst for the recombination of $\mathrm{H} \cdot$ atoms (5).

The removal of $\mathrm{OH} \cdot$, by replacement with the less reactive $\mathrm{Br}$, , blocks the main heat release step of hydrocarbon combustion, the conversion of $\mathrm{CO}$ to $\mathrm{CO}_{2}$ (10) [24].

$$
\mathrm{CO}+\cdot \mathrm{OH} \leftrightarrows \mathrm{CO}_{2}+\mathrm{H} \cdot
$$

Thus, loss of $\mathrm{H} \cdot$ and $\mathrm{OH} \cdot$ will increase the yield of carbon monoxide and other products of incomplete combustion. The $\mathrm{H} \cdot$ and $\cdot \mathrm{OH}$ radicals are also essential for many other flame reactions.

Kinetic reaction schemes predict that $\mathrm{HBr}$ must be recycled around 7 times in order to account for the observed flame inhibition [25]. Thus the hydrogen halide is regenerated by further reaction with another fuel hydrocarbon (4).

In the presence of antimony oxide $\left(\mathrm{Sb}_{2} \mathrm{O}_{3}\right)$, the efficiency of halogenated flame retardants is significantly improved, although antimony has no flame retardant effect on its own. $\mathrm{SbBr}_{3}$ is believed to form via the intermediate $\mathrm{SbOBr} . \mathrm{Sb}_{2} \mathrm{O}_{3}$ and $\mathrm{HBr}$ first yield $\mathrm{SbOBr}$, which gives off $\mathrm{SbBr}_{3}$ over a relatively wide temperature range. The individual endothermic stages ensure that the system is cooled. $\mathrm{SbBr}_{3}$, as the actual flame retardant, acts as a radical interceptor like $\mathrm{HCl}$ or $\mathrm{HBr}$. It is thought that the trivalent antimony halide facilitates the formation of halogen radicals, and is more effective than $\mathrm{HBr}[26]$ at catalysing the recombination of hydrogen.

\subsection{Flame retardant mechanism of alkyl phosphinate/melamine polyphosphate systems}

PA 6.6, flame retarded with AIPi decomposes, releasing diethyl phosphinic acid (11); at lower heat fluxes in the cone calorimeter AlPi decomposes in the vapour phase, at higher heat fluxes, diethylphosphinic acid is released from the condensed phase [16]. 


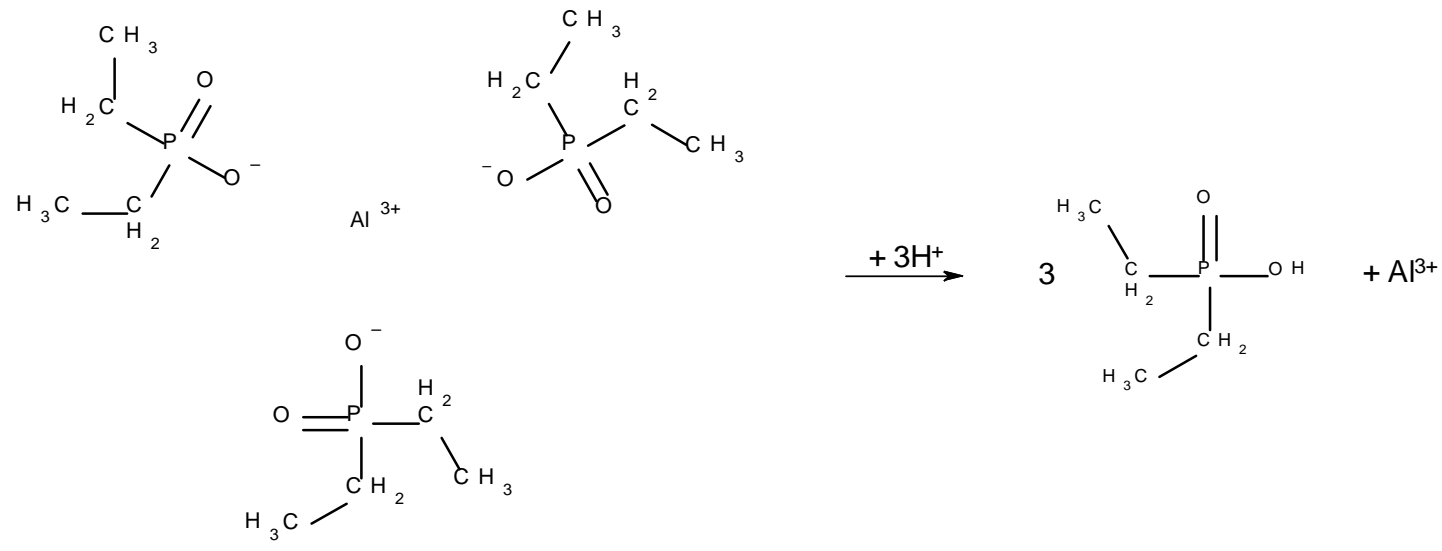

Using similar loadings to the materials in the current study (30\% glass fibre but only $18 \%$ total fire retardant loading), resulted in residues of $6-8 \%$ in addition to glass fibre, when AIPi, MPP or a mixture were present [16]. Moreover, they confirmed the release of diethylphosphinic acid by thermogravimetric analysis, coupled to Fourier transform infrared (TGA-FTIR) $\left(3650 \mathrm{~cm}^{-1}(\mathrm{PO}-\mathrm{H})\right.$, $1275 \mathrm{~cm}^{-1}(\mathrm{P}=0), 1243 \mathrm{~cm}^{-1}(\mathrm{P}-\mathrm{C})$, and $850 \mathrm{~cm}^{-1}(\mathrm{P}-\mathrm{O})$ ) for both PA 6.6/AIPi and PA 6.6/AIPiM materials. In addition, aluminium phosphates were identified in the residue, and it was assumed that melamine phosphinate may also be present in the vapour [16]. However, a more recent study using TGA FTIR of PA 6 with AIPiM found no evidence for phosphates in the vapour phase under thermo-oxidative conditions [27]. In addition, further details were reported of the contribution made by phosphates to increase the char yield. The increased residue yields incorporating aluminium phosphate [16] and the chemical composition of the residue [27] points to a condensed phase mechanism, whereas the release of diethyl phosphinic acid is strongly suggestive of a gas phase mechanism.

AlPi was shown to reduce the heat release rate of PA 6.6 by inhibition of flaming combustion, while increasing the $\mathrm{CO}$ production rate. This gas phase inhibition effect was also evident, but less distinct, for PA 6.6/AIPiM. Thus, both condensed and gas phase mechanisms have been demonstrated.

A related and well-studied gas phase flame retardant, dimethylmethylphosphonate (DMMP) has been reported to decompose via $\mathrm{CH}_{3} \mathrm{PO}_{2}$. This species was proposed, as a key intermediate in the combustion reactions of DMMP, based on a mass spectrometric investigation $\left(\mathrm{CH}_{3} \mathrm{P}(=\mathrm{O})_{2} \mathrm{~m} / \mathrm{z}\right.$ 78) [28]. This hypothetical structure has been supported by a detailed theoretical investigation using molecular orbital calculations [29]. We propose that AIPi may follow the same pathway, releasing ethane (12).

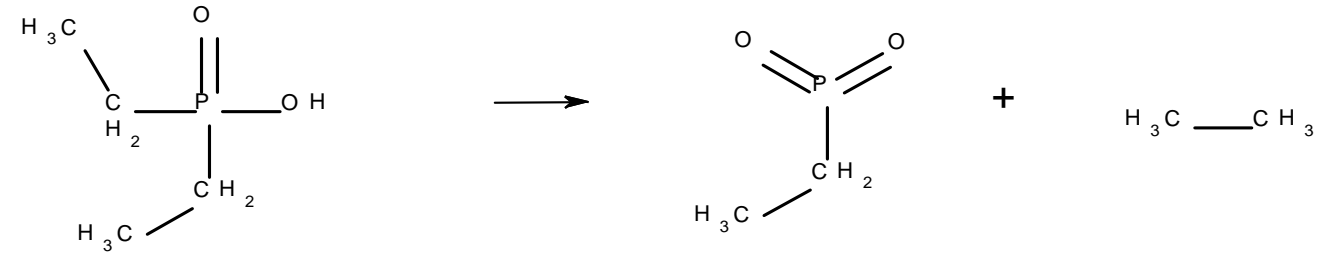

This intermediate decomposes further to generate HOPO and ethane (13). 
<smiles>CCP(=O)=O</smiles>

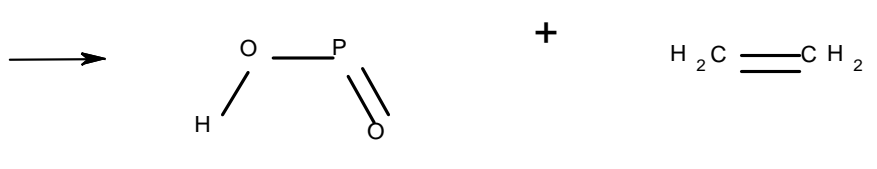

Ethane and ethene have both been reported in the decomposition of PA 6.6/AIPiM [16]. The cisstructure of the HOPO intermediate (13) has been predicted to be the lowest energy isomer, based on molecular orbital calculations [30].

$\mathrm{HOPO}, \mathrm{HOPO}_{2}$, and the $\mathrm{PO}_{2} \cdot$ radical are all known to be very effective free radical trapping agents [31]. Their inhibition of flames has been investigated and modelled by Babushok et al [31]. He has shown that phosphorus containing species such as $\mathrm{HPO}, \mathrm{PO} \cdot \mathrm{PO}_{2} \cdot$, $\mathrm{HOPO}$ and $\mathrm{HOPO}_{2}$ catalytically recombine $\mathrm{H} \cdot$ and $\cdot \mathrm{OH}$. Since the simple phosphorus-containing species participate in the main inhibition reactions, the form of the parent compound is probably unimportant.

$$
\begin{array}{lll}
\cdot \mathrm{OH}+\mathrm{HOPO} & \leftrightarrows & \mathrm{H}_{2} \mathrm{O}+\mathrm{PO}_{2} \cdot \\
\mathrm{H} \cdot+\mathrm{HOPO} & \leftrightarrows & \mathrm{H}_{2}+\mathrm{PO}_{2} \cdot \\
\cdot \mathrm{O}+\mathrm{HOPO} & \leftrightarrows & \cdot \mathrm{OH}+\mathrm{PO}_{2} \cdot \\
\cdot \mathrm{OH}+\mathrm{PO}_{2} \cdot \mathrm{M} & \leftrightarrows & \mathrm{HOPO}_{2}+\mathrm{M} \\
\mathrm{PO}_{2} \cdot+\mathrm{H} \cdot+\mathrm{M} & \leftrightarrows & \mathrm{HOPO}+\mathrm{M}
\end{array}
$$

This cycle shows that while $\mathrm{H} \cdot$ and $\cdot \mathrm{O} \cdot$ are consumed, $\cdot \mathrm{OH}$ is both consumed and regenerated. Numerical calculations and sensitivity analysis show that the burning velocity is most sensitive to the rate constants of the two recombination reactions of the $\mathrm{PO}_{2}$. radical (reactions 17 and 18).

\subsection{Temperature dependence of gas-phase inhibition}

Inhibition of flaming combustion by scavenging $\mathrm{H} \cdot, \cdot \mathrm{OH}$ and $\cdot \mathrm{O} \cdot$ radicals is temperature dependent. Higher temperatures will generally lead to an increase in all free radical concentrations, from entropy considerations.

A preliminary study [32] in the SSTF using the same PA 6/BrSb formulation reported here showed a modest reduction of $\mathrm{CO}$ yield at a furnace temperature of $825^{\circ} \mathrm{C}$, and a large reduction at $950{ }^{\circ} \mathrm{C}$, in well-ventilated conditions. A related SSTF study on the CO yield from PVC (where CO formation is believed to be inhibited by $\mathrm{Cl}$. radicals) also showed a significant reduction in $\mathrm{CO}$ yield at $950{ }^{\circ} \mathrm{C}$, again, under well-ventilated conditions [33].

The current work in the steady state tube furnace showed a reduction in gas phase inhibition by phosphorus at higher furnace temperatures. Gas phase inhibition was also reduced at higher applied heat fluxes in the cone calorimeter [16]. Assuming that the higher heat fluxes give rise to higher temperatures in the gas phase, this corresponds to reported work on the temperature dependency for phosphorus-based flame inhibition [34]. The effect of DMMP on the relative $\cdot \mathrm{OH}$ concentration profiles was measured using quenching-corrected Laser-Induced Fluorescence (LIF) [35]. As the stoichiometric adiabatic flame temperature increased there was a strong decrease in the 
magnitude of the reduction in $\mathrm{OH}$ concentration. Kinetic calculations show that inhibition is due to the phosphorus-containing radical $\cdot \mathrm{PO}_{2}$, and $\mathrm{HOPO}$ and $\mathrm{HOPO}_{2}$, formed after the decomposition of the parent compound; reactions involving phosphorus remove $\mathrm{H} \cdot$ and $\cdot \mathrm{O} \cdot$ atoms from the radical pool, thus weakening the flame. These reactions produce $\cdot \mathrm{OH}$ directly, and the $\cdot \mathrm{OH}$ concentrations are only indirectly reduced through reduction of $\cdot \mathrm{O} \cdot$ and $\mathrm{H} \cdot$ concentrations.

\subsubsection{Hydrogen cyanide formation and destruction in fires}

The increased yield of $\mathrm{CO}$ in the current work follows directly from the inhibition of the free radical reactions by trapping active radicals such as $\mathrm{H} \cdot$ and $\cdot \mathrm{OH}$. The increased yield of $\mathrm{HCN}$ by halogens, requires a clearer understanding of $\mathrm{HCN}$ formation and destruction in flames.

$\mathrm{HCN}$ is a flammable gas with a lower explosive (ignitability) limit of $5.6 \%$ in air. In atmospheric science, biomass burning is the main source of atmospheric $\mathrm{HCN}$ [36]; similar to $\mathrm{CO}$, it is removed from the atmosphere by reaction with the hydroxyl $(\cdot \mathrm{OH})$ radical. Combustion of nitrogenous materials releases nitrogen as $\mathrm{HCN}$ and ammonia $\left(\mathrm{NH}_{3}\right)$, producing nitrous oxide $\left(\mathrm{N}_{2} \mathrm{O}\right)$ and nitric oxide (-NO). As the ratio of oxygen to nitrogen in the fuel increases, so the $\mathrm{HCN} / \mathrm{NH}_{3}$ and $\mathrm{N}_{2} \mathrm{O} / \mathrm{NO}$ ratios decrease. Higher equivalence ratios and heating rates, and temperatures above $727^{\circ} \mathrm{C}$ favour HCN formation [36]

Reports of a novel study [37, 38] on HCN generation from combustion of polyamide 6.6 in the steady state tube furnace provide additional insight into the processes of $\mathrm{HCN}$ formation and destruction. In these experiments, infrared polarisation spectroscopy was used to measure the concentration of $\mathrm{HCN}$ inside the furnace tube, both close to the flame, and in the cool zone towards the exit of the furnace tube. Different fire conditions were investigated. In each case, the highest HCN concentrations were observed above the flame zone, and these diminished significantly for low temperature, well-ventilated flaming, and also for under-ventilated flaming at high temperature, but diminished least for small under-ventilated flaming (Stage 3a in Table 1).

Currently accepted mechanisms, described in detail elsewhere, [36] indicate that $\mathrm{HCN}$ oxidises via a complex set of reactions, yielding $\mathrm{NO}, \mathrm{N}_{2} \mathrm{O}, \mathrm{N}_{2}, \mathrm{CO}, \mathrm{CO}_{2}$ and water. A detailed scheme involving 41 species and 250 reversible reactions has been proposed [36] and validated through numerous experimental studies. Sensitivity analysis was used to identify the most important steps of mechanism. These include the hydrogen-oxygen chain branching steps, reactions 1, 2 (described earlier) and 19, a third-body recombination reaction.

$$
\mathrm{H} \cdot+\mathrm{O}_{2}+\mathrm{M} \leftrightarrows \mathrm{HO}_{2} \cdot+\mathrm{M}
$$

Initially, $\mathrm{HCN}$ reacts with the $\cdot \mathrm{OH}$ radicals to form cyanide radicals $(\cdot \mathrm{CN})$

$$
\mathrm{HCN}+\cdot \mathrm{OH} \leftrightarrows \quad \cdot \mathrm{CN}+\mathrm{H}_{2} \mathrm{O}
$$

These are then oxidised to the isocyanate radical $(\cdot \mathrm{NCO})$ by $\mathrm{OH} \cdot$ and $\mathrm{O}_{2}$

$$
\begin{aligned}
& \cdot \mathrm{CN}+\cdot \mathrm{OH} \leftrightarrows \\
& \cdot \mathrm{CN}+\mathrm{O}_{2} \leftrightarrows \\
& \cdot \mathrm{NCO}+\mathrm{NCO}+\cdot \mathrm{O} \cdot
\end{aligned}
$$


The isocyanate radical then combines with $\cdot \mathrm{O} \cdot$ to form $\cdot \mathrm{NO}$ and $\mathrm{CO}(23)$, or with nitric oxide to form $\mathrm{N}_{2} \mathrm{O}, \mathrm{N}_{2}, \mathrm{CO}$ and $\mathrm{CO}_{2}(24,25)$. $\cdot \mathrm{NO}$ is a stable free radical which exists as a gas at room temperature.

$$
\begin{aligned}
& \cdot \mathrm{NCO}+\cdot \mathrm{O} \cdot \leftrightarrows \\
& \cdot \mathrm{NCO}+\cdot \mathrm{NO} \leftrightarrows \mathrm{N}_{2} \mathrm{O}+\mathrm{CO} \\
& \cdot \mathrm{NCO}+\cdot \mathrm{NO} \leftrightarrows \mathrm{N}_{2}+\mathrm{CO}_{2}
\end{aligned}
$$

$\mathrm{HCN}$ may also undergo reaction with $\cdot \mathrm{OH}$ to become cyanuric acid (HOCN) (26) which exists as a stable, non-toxic solid trimer, or isocyanuric acid (HNCO) (27) which readily hydrolyses (28).

$$
\begin{aligned}
& \mathrm{HCN}+\cdot \mathrm{OH} \leftrightarrows \mathrm{HOCN}+\mathrm{H} \cdot \\
& \mathrm{HCN}+\cdot \mathrm{OH} \leftrightarrows \mathrm{HNCO}+\mathrm{H} \cdot \\
& \mathrm{HNCO}+\mathrm{H}_{2} \mathrm{O} \leftrightarrows \mathrm{CO}_{2}+\mathrm{NH}_{3}
\end{aligned}
$$

Reactions 29 and 30 are also important, but only under fuel rich conditions [36].

$$
\begin{array}{lll}
\mathrm{HCN}+\cdot \mathrm{O} \cdot & \leftrightarrows & \mathrm{CN}+\mathrm{H}_{2} \mathrm{O} \\
\mathrm{HCN}+\mathrm{M} \text { or } \mathrm{H} \cdot & \leftrightarrows & \mathrm{HNC}+\mathrm{M} \text { or } \mathrm{H} .
\end{array}
$$

This mechanism underlines the critical role played by the $\cdot \mathrm{OH}$ radical in the oxidation of $\mathrm{HCN}$, particularly in well-ventilated conditions.

\subsection{Effects of AlPiM and BrSb on toxic products yields of PA 6 and PA 6.6}

The critical role played by the $\mathrm{OH} \cdot$ radical in reducing the concentration of $\mathrm{CO}$ and $\mathrm{HCN}$, and hence the toxicity of fire effluents has been demonstrated. In addition to its unique role in oxidising $\mathrm{CO}$ to $\mathrm{CO}_{2}$ (reaction 10), it is also essential to the effective destruction of $\mathrm{HCN}$ (reactions 20, 26 and 27 in the current work). This has been demonstrated experimentally in the steady-state tube furnace in well-ventilated fires involving polyamides. The higher yields of both HCN and $\mathrm{CO}$ seen in wellventilated flames of polyamides protected with brominated flame retardants and an antimony oxide synergist, presumably result from the removal of the $\mathrm{OH}$ - radical from the flame zone. Moreover, the lower yields from PA formulations fire retarded by aluminium phosphinate/melamine polyphosphate combinations especially at higher temperatures, is a direct consequence of the different flame retardant mechanism of phosphorus, which only indirectly reduces the $\cdot \mathrm{OH}$ concentration, and achieves its flame quenching effects from reducing the $\mathrm{H} \cdot$ and $\cdot \mathrm{O}$ - concentrations. Thus, this new generation of gas phase flame retardants, based on AIPi and MPP, not only reduce the ignitability and flame spread, they do so without a significant detrimental impact on the fire toxicity. 


\section{Conclusions}

Although the overall number of casualties from fires have decreased, deaths and injuries from inhalation of toxic fire effluents, as a proportion of total fire victims, has continuously increased since the 1960s, for example, as reported in the UK fire statistics [1]. It has already been established and reported that carbon monoxide yields are increased by gas phase flame retardants, and by under-ventilation. Moreover, it has been shown that hydrogen cyanide yields also increase as fires become under-ventilated.

This work clearly shows that HCN is the major contributor to the toxicity for all fire retarded PA materials reported here, even in well-ventilated conditions, although the contribution from CO from the $\mathrm{BrSb}$ materials is also significant. This work shows that when comparing two formulations of comparable flammability, the one with the flame retardant containing bromine and antimony causes a significant increase in the fire toxicity, compared to the material flame retarded by the aluminium phosphinate/melamine polyphosphate blend. It demonstrates, for the first time, how hydrogen cyanide yields from aliphatic polyamides increase tenfold in the presence of a brominated flame retardant and antimony oxide, but only modestly, around twofold, in the presence of AIPiM. This has clear implications for fire safety: a fire of a $1 \mathrm{~kg}$ PA 6 fuse box flame retarded with the BrSb combination would produce a lethal effluent in a $10 \mathrm{~m} \times 10 \mathrm{~m} \times 3 \mathrm{~m}$ enclosure, where the same fuse box fire retarded with AIPiM would only produce a lethal volume of effluent for a $4.5 \mathrm{~m} \times 5 \mathrm{~m} \times 3 \mathrm{~m}$ enclosure. Thus while both fire retardant combinations reduce the risk of fire, if a fire does occur, the use of BrSb increases the hazard by increasing the fire toxicity much more than the AIPiM. Unfortunately, the development of brominated polystyrene to replace the current generation of brominated flame retardants has been shown to significantly increase the fire hazard. It also shows a positive correlation between furnace temperature and toxicity for the BrSb system, but a strongly negative correlation for AIPiM with furnace temperature, for both PA 6 and PA 6.6.

Bringing studies of flame retardant mechanisms together with gas phase kinetics of HCN formation and destruction has provided a crucial insight into the cause of this behaviour, through the differences in the gas phase inhibition mechanisms of the BrSb and AlPiM systems. In particular, the preferential trapping of the $\mathrm{H} \cdot$ and $\cdot \mathrm{O} \cdot$ radicals by AIPiM, leaving the $\cdot \mathrm{OH}$ radicals to oxidise the $\mathrm{HCN}$ and $\mathrm{CO}$ explains the significant reduction in fire effluent toxicity. The temperature effect of the phosphorus flame retardant systems provides crucial supporting evidence.

This study comes at a time when there is considerable pressure to eliminate all brominated flame retardants from consumer-products and replace them with safer alternatives. It presents experimental data, together with a detailed explanation which shows a significant fire safety advantages to replacing brominated flame retardants with aluminium phosphinate/melamine polyphosphate combinations. Brominated flame retardants have been shown to increase the yields of the two biggest killers in fires ( $\mathrm{CO}$ and $\mathrm{HCN}$ ), where their phosphinate replacements actually show a reduction in the fire toxicity, most notably as the fire grows and the temperature increases.

\section{Acknowledgements}

This work was followed from the European project STREP FP-6 PredFire-Nano 'Predicting Fire Behaviour of Nanocomposites from Intrinsic Properties' under the contract STREP 013998, with 
technical and financial support from Clariant Produkte (Deutschland) $\mathrm{GmbH}$, a member of the PREDFIRE consortium. One of us (SAM) would like to thank the University of Central Lancashire for provision of PhD studentship.

1 Fire Statistics United Kingdom 2008, Department for Communities and Local Government, London, 2010 (and preceeding editions).

2 Stec AA, Hull TR (Editors), Fire Toxicity, Woodhead Publishing, Cambridge, UK and CRC Press, Boca Raton, 2010.

3 Stec AA, Hull TR, Lebek K, Purser JA, Purser DA. The effect of temperature and ventilation condition on the toxic product yields from burning polymers. Fire Mater 2008;32:49-60.

4 Alarie Y. Toxicity of fire smoke. Crit Rev Toxicol 2002;32:259-89.

5 Purser D. Toxicity of fire retardants in relation to life safety and environmental hazards, in Fire retardant materials, Edited by A R Horrocks and D Price, Woodhead publishing, Cambridge, UK 2001.

6 Braun E, Gann R G, Levin B C, and Paabo M, Combustion Product Toxic Potency Measurements: Comparison of a Small Scale Test and "Real-World" Fires, Journal of Fire Sciences 1990 8: 63-79

7 ISO 19706:2007 Guidelines for assessing the fire threat to people

8 Pitts WM. The global equivalence ratio concept and the formation mechanisms of carbon monoxide in enclosure fires. Progress in Energy and Combustion Science 1995;21:197-237

9 Hull TR, Paul KT, Bench-scale assessment of combustion toxicity - A critical analysis of current protocols, Fire Safety Journal, 2007; 42: 340-365.

10 ISO TS 19700:2007 Controlled equivalence ratio method for the determination of hazardous components of fire effluents

11 Stec AA, Hull TR, Lebek K. Characterisation of the steady state tube furnace (ISO TS 19700) for fire toxicity assessment. Polym Degrad Stab 2008;93:2058-65.

12 ISO 13344:2004 Estimation of the lethal toxic potency of fire effluents

13 ISO 13571:2012 Life threat from fires - Guidance on the estimation of time available for escape using fire data.

14 Hull TR, Stec AA, Lebek K, Price D. Factors affecting the combustion toxicity of polymeric materials. Polym Degrad Stab 2007;92:2239-46.

15 Stec AA, Hull TR. Assessment of the fire toxicity of building insulation materials. Energy Build 2011;43:498-506.

16 Braun U, Schartel B, Fichera MA, Jäger C. Flame retardancy mechanisms of aluminium phosphinate in combination with melamine polyphosphate and zinc borate in glass-fibre reinforced polyamide 6,6. Polym Degrad Stab 2007;92:1528-45.

17 Levchik, S. V., and Weil, E. D., A Review of Recent Progress in Phosphorus-based Flame Retardants, Journal of Fire Sciences, 24, 345, (2006)

18 de Wit CA. An overview of brominated flame retardants in the environment, Chemosphere, 46, $583,(2002)$.

19 Shaw SD, Blum A, Weber R, Kannan K, Rich D, Lucas D, Koshland CP, Dobraca D, Hanson S, Birnbaum LS. Halogenated flame retardants: Do the fire safety benefits justify the risks? Rev Environ Health 2010;25:261-305.

20 Birnbaum LS, Staskal DF. Brominated flame retardants: Cause for concern? Environ Health Perspect 2004;112:9-17.

21 J DiGangi, A Blum, Å Bergman, C. A. de Wit, D Lucas, D Mortimer, A Schecter, M Scheringer, S D. Shaw and T. F. Webster San Antonio Statement on Brominated and Chlorinated Flame Retardants, Environmental Health Perspectives, 118, A 516-536, 2010.

22 Newton PE; Schroeder RE; Zwick L; Serex T; Inhalation Developmental Toxicity Studies In Rats With Antimony Trioxide (Sb2O3). Toxicologist 2004 Mar;78(1-S):38 
23 Hull TR, Carman JM, Purser DA. Prediction of CO evolution from small-scale polymer fires. Polym Int 2000;49:1259-65.

24 A Schnipper, L Smith-Hansen, S E Thomsen, Reduced Combustion Efficiency of Chlorinated Compounds, Resulting In Higher Yields of Carbon Monoxide, Fire and Materials,19, 61-64, (1995).

25 Babushok, V. Tsang, W., Linteris, G. T., and Reinelt, D. (1998) Chemical Limits to Flame Inhibition, Combustion and Flame, 115:551-560.

26 Linteris GT, Rumminger MD, Babushok VI. Catalytic inhibition of laminar flames by transition metal compounds. Progress in Energy and Combustion Science 2008;34:288-329.

27 Samyn F, Bourbigot S. Thermal decomposition of flame retarded formulations PA6/aluminum phosphinate/melamine polyphosphate/organomodified clay: Interactions between the constituents? Polym Degrad Stab 2012;97:2217-30.

28 Werner JH, Cool TA. Kinetic model for the decomposition of DMMP in a hydrogen/oxygen flame. Combust Flame. 1999;117:78-98.

29 Kan W, Zhong $\mathrm{H}, \mathrm{Yu} \mathrm{H}$. Theoretical prediction regarding structural and thermodynamical characteristics of stable $\mathrm{CH} 3 \mathrm{PO} 2$ isomers and unimolecular decomposition mechanisms of species $\mathrm{CH} 3 \mathrm{P}(=\mathrm{O}) 2, \mathrm{CH} 3 \mathrm{O}-\mathrm{P}=\mathrm{O}$, and $\mathrm{CH} 2=\mathrm{P}(=\mathrm{O}) \mathrm{OH}$. Journal of Computational Chemistry. 2009;30:2334-2350.

30 Brinkmann, N. R., and Carmichael, I., B3LYP Investigation of HPO2, trans-HOPO, cis-HOPO, and Their Radical Anions, J. Phys. Chem. A, 108, 9390-9399, (2004).

31 Babushok, V., and Tsang, W., Influence of Phosphorus-Containing Fire Suppressants on Flame Propagation, Proc. Third Int. Conf. on Fire Res. and Eng., Chicago, IL, p. 257-267 (1999).

32 Kaczorek, K.; Stec, A. A.; Hull, T. R. Carbon monoxide generation in fires: Effect of temperature on halogenated and aromatic fuels; Fire Safety Science; 2011; 10, 253-263.

33 Kaczorek K, Stec AA, Hull TR. Carbon monoxide generation in fires: Effect of temperature on halogenated and aromatic fuels. Fire Safety Science. 2011:253-263

34 Hastie, J. W. and Bonnell, D. W., Molecular Chemistry of Inhibited Combustion Systems, National Bureau of Standards, Final NBSIR 80-2169; PB81-170375, (1980).

35 M.A. MacDonald, F.C. Gouldin and E.M. Fisher, Temperature dependence of phosphorus-based flame inhibition, Combustion and Flame, 124, 668-683, (2001).

36 Dagaut, P., Glarborg, P., Alzueta, M. U., The oxidation of hydrogen cyanide and related chemistry, Progress in Energy and Combustion Science 2008; 34: 1-46.

37 Sun ZW, Försth M, Li ZS, Li B, Aldén M. Mid-infrared polarization spectroscopy: A tool for in situ measurements of toxic gases in smoke-laden environments, Fire and Mater, 2011; 35: 527-537.

38 Sun Z, Försth M, Li Z, Li B, Aldén M, In situ Measurements of HCN in a Tube Furnace with Infrared Polarization Spectroscopy, Fire Safety Sci, 2011; 10. 